\title{
Modelo Black-Litterman con Support Vector Regression: una alternativa para los fondos de pensiones obligatorios colombianos
}

\section{Black-Litterman Model with Support Vector Regression: An alternative for colombian pension funds}

Julián Andrés Buriticá-Mejía*

* $\quad$ Magíster en Finanzas, Universidad Externado de Colombia. Gestor de Operaciones 302 grado 6. Administradora de los Recursos del Sistema General de Seguridad Social en Salud (ADRES) [julianandresburiticamejia@gmail.com], [ORCID: 0000-0003-3238-6828].

Artículo recibido el 01 de abril de 2020.

Aceptado el 01 de mayo de 2020.

Para citar este artículo:

Buriticá-Mejía, J. A. (2020). Modelo Black-Litterman con Support Vector Regression: una alternativa para los fondos de pensiones obligatorios colombianos. ODEON, 18, 205-257. DOI: https://doi.org/10.18601/17941113.n18.06 


\section{Resumen}

El modelo pensional colombiano se caracteriza por ser intergeneracional, razón por la cual se ha visto afectado por tres grandes problemas estructurales: inequidad, baja cobertura e insostenibilidad financiera. Frente a este panorama, el Estado ha reaccionado con medidas de tipo normativo que han aliviado algunos de estos problemas; sin embargo, estas regulaciones prudenciales han impactado la finalidad inherente a un fondo de inversión, es decir, la generación de riqueza para garantizar el consumo intertemporal de la población colombiana en edad de retiro. En consecuencia, los fondos de pensiones en Colombia requieren que, bajo el marco de las diferentes regulaciones, se estudien nuevas alternativas de estructuración de sus portafolios que les permitan un eficiente manejo de los recursos de retiro para su población.

En este sentido, se creó una frontera y un portafolio eficientes mediante la aplicación de Support Vector Machine sobre el modelo Black-Litterman para los fondos de pensiones obligatorios colombianos, con el fin de comprobar la utilidad de los algoritmos de aprendizaje en los diferentes ámbitos financieros. Los resultados muestran que es posible su aplicabilidad al modelo de estructuración de portafolios Black-Litterman mediante mejoras a la matriz de las distribuciones a priori, puntualmente con el uso de Support Vector Regression, que generó portafolios mejor diversificados frente al modelo media varianza de Markowitz, y que son adaptables a los fondos de pensiones obligatorios colombianos.

Palabras clave: Black-Litterman; media varianza Markowitz; Support Vector Regression; fondos de pensiones obligatorios colombianos; portafolios.

Clasificación JEL: C53, C63, G11, G23.

\section{Abstract}

The Colombian pension model is characterized by being intergenerational, reason why it has been affected by three major structural problems: inequality, low coverage and financial unsustainability, to which the Colombian government has reacted with regulatory measures that have somewhat relieved these problems. However, these prudential regulations have a negative effect on the inherent purpose of the investment fund, which is the generation of wealth to guarantee the intertemporal consumption of the Colombian elderly population. Therefore, the pension funds in Colombia requires that under the framework of the stablished regulations, new alternatives for structuring their portfolios be 
studied that allow them into better and more efficient management of retirement resources for Colombian people.

In this sense, an efficient portfolio and frontier were built through a Support Vector Machine and the Black Litterman model to the Colombian Mandatory Pension Funds, with the aim to test the applicability of machine learning in financial fields. Results show that its applicability to the Black-Litterman portfolio structuring model is suitable through the improvement to the a priori distribution matrix, specifically with the use of Support Vector Regression, the model generated better diversified portfolios in comparison to the Markowitz model and shows to be adaptable to the Colombian Mandatory Pension Funds.

Keywords: Black-Litterman; Markowitz media variance; Support Vector Regression; colombian mandatory pension funds; portfolios.

Classification JEL: C53, C63, G11, G23.

\section{Introducción}

Las pensiones en Colombia datan desde la creación, en 1945, del Instituto Colombiano de Seguros Sociales (ICSS), focalizado en los servidores públicos; solo 22 años después se hicieron extensivas al sector privado y contemplaron pensiones por vejez, invalidez y muerte. Se caracterizó por ser un modelo intergeneracional, de tal manera que las generaciones más jóvenes constituyen un pasivo que debe ser solventado con las contribuciones de las generaciones futuras (Villar, Malagón, Vaca y Ruiz, 2013). Las funcionalidades del sistema, que se caracterizaba por mayores beneficios hacia el sector público y el incumplimiento de aportes por parte del Estado para solventar el sistema, así como los cambios en la esperanza de vida y en natalidad, llevaron a su insostenibilidad hasta el punto de comprometer el $200 \%$ del producto interno bruto (PIB).

En cuanto a cambios en esperanza de vida, en el último censo realizado por el Departamento Administrativo Nacional de Estadística (DANE) se puede observar de forma comparativa, por cortes de edad, cómo se va aplanando, lo que indica una reducción en la población que cotiza a su vez que la expectativa de vida de la población en edad de pensionarse va en aumento; este descalce repercute en la estabilidad financiera del sistema pensional (figura 1). 
Figura 1: Distribución de la población

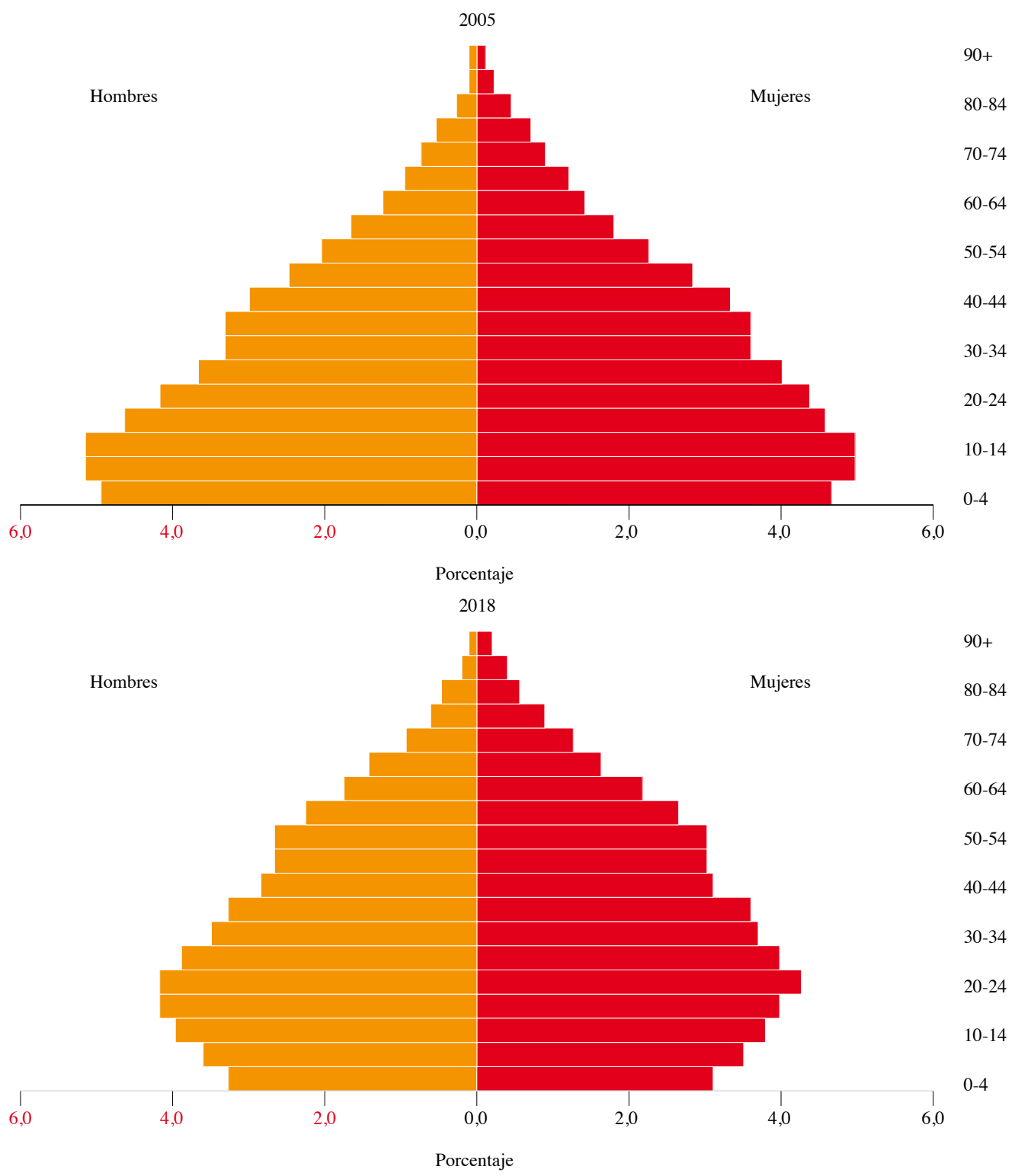

Fuente: DANE (2018).

Dentro de los problemas estructurales, quizá el que más demanda estudio y del cual se encuentra una literatura más amplia es el referente a mercado laboral y demografía que, en últimas, es desde donde provienen los problemas 
de cobertura, pues los diversos ciclos de mercado laboral en donde se puede segmentar por grado de educación e incluso ubicación -rural, urbano-, y los aportes que en diferentes etapas del ciclo laboral realiza el cotizante impactan tanto en la población en edad de pensionarse como en el Estado vía recursos públicos por la necesidad de subsidiar la pensión.

Al respecto, se encuentra un análisis del ciclo de vida laboral, donde la brecha de la dinámica laboral se acentúa más según el grado de instrucción en educación superior, donde la tendencia de empleo que requiere menor nivel de educación sufre un reemplazo permanente por aquel que requiere mayor nivel; los jóvenes inician su carrera laboral como asalariados con altas tasas de rotación y desempleo, y terminan en empleos independientes e informales, de tal manera que en la época temprana aportan al sistema pensional con base en sueldos mejores, y en la etapa final, con bajos ingresos, dejan de cotizar (López y Valderrama, 2012), estos resultados se evidencian en la figura 2. Así, "población sin educación superior: se vincula más temprano al mercado laboral y se retira más temprano. Frente a los más educados su participación laboral es menos desde los 25 años, en todas las edades el empleo asalariado es menor y el no asalariado es mayor" (López y Valderrama, 2012).

Figura 2: Ciclo laboral

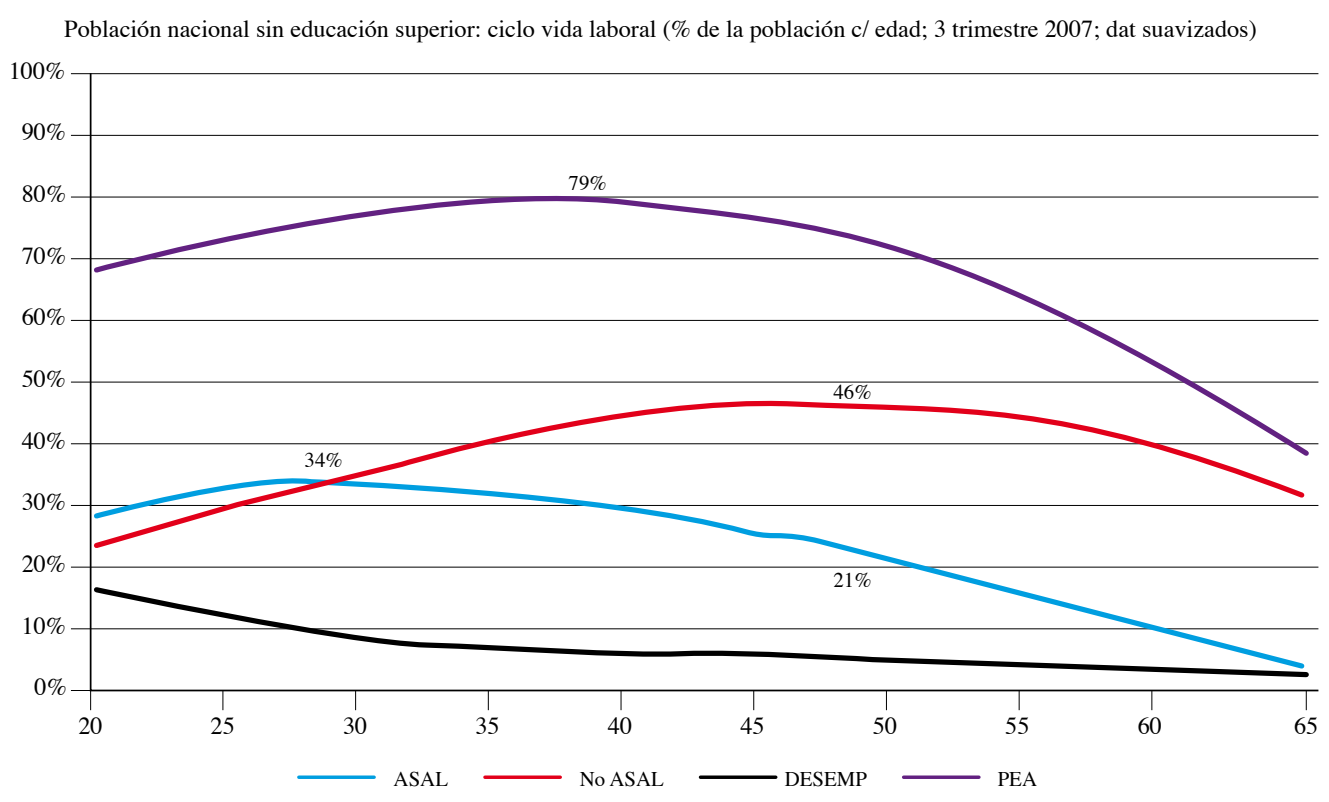


Población nacional sin educación superior: ciclo vida laboral (\% de la población c/ edad; 3 trimestre 2007; dat suavizados)

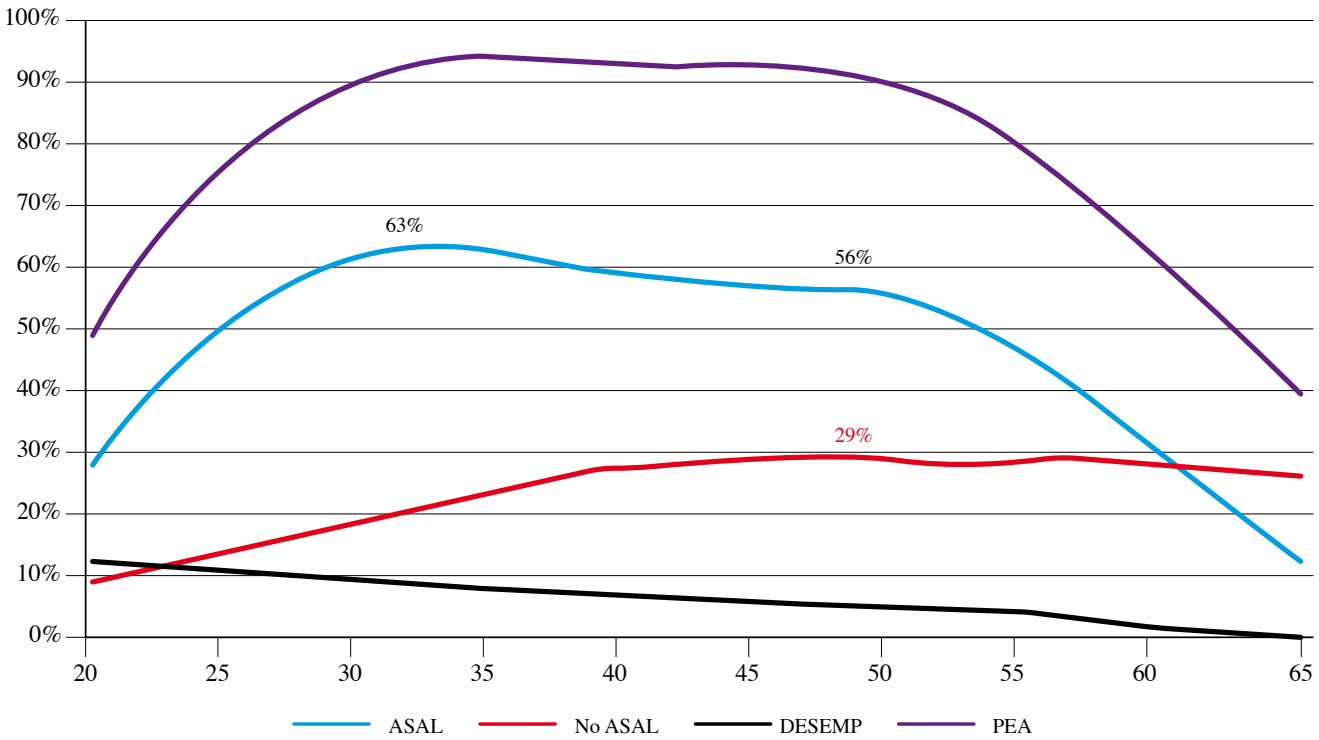

Población nacional sin educación superior: ciclo vida laboral (\% de la población c/ edad; 3 trimestre 2007; dat suavizados)

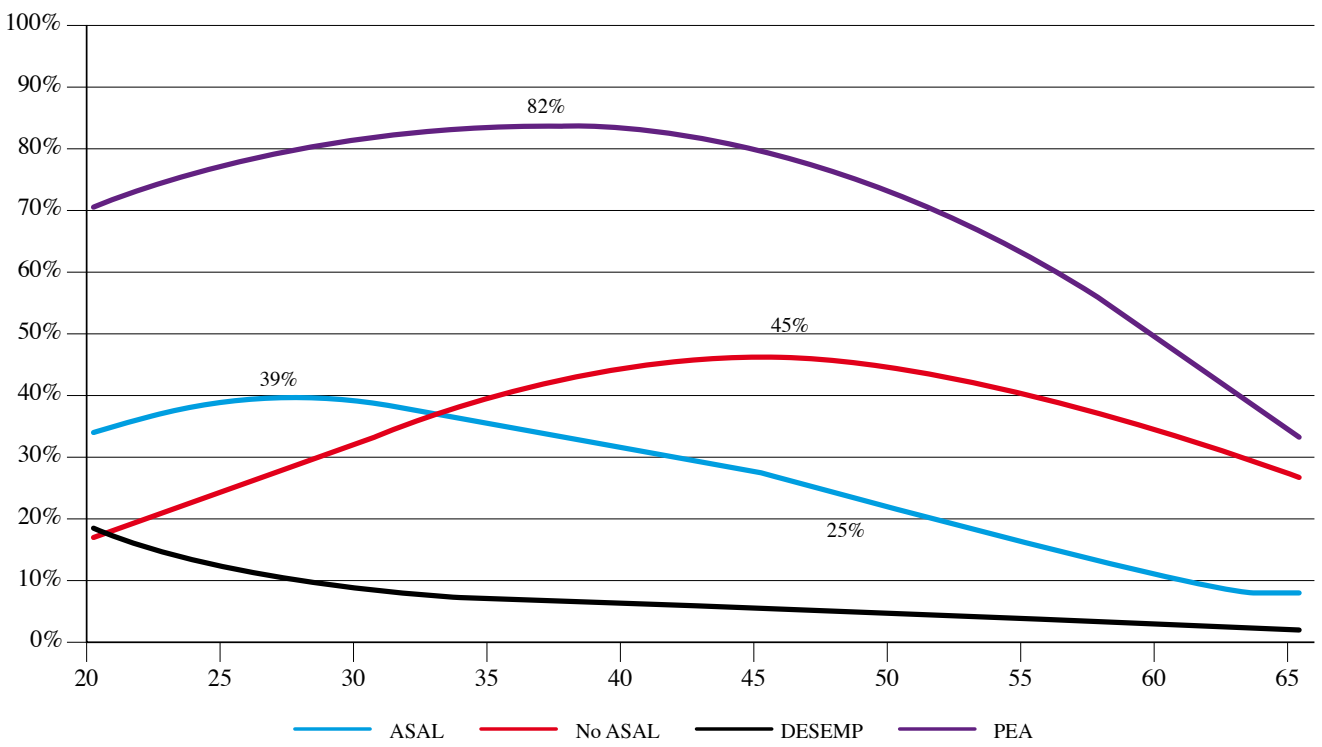


Población nacional sin educación superior: ciclo vida laboral (\% de la población c/ edad; 3 trimestre 2007; dat suavizados)

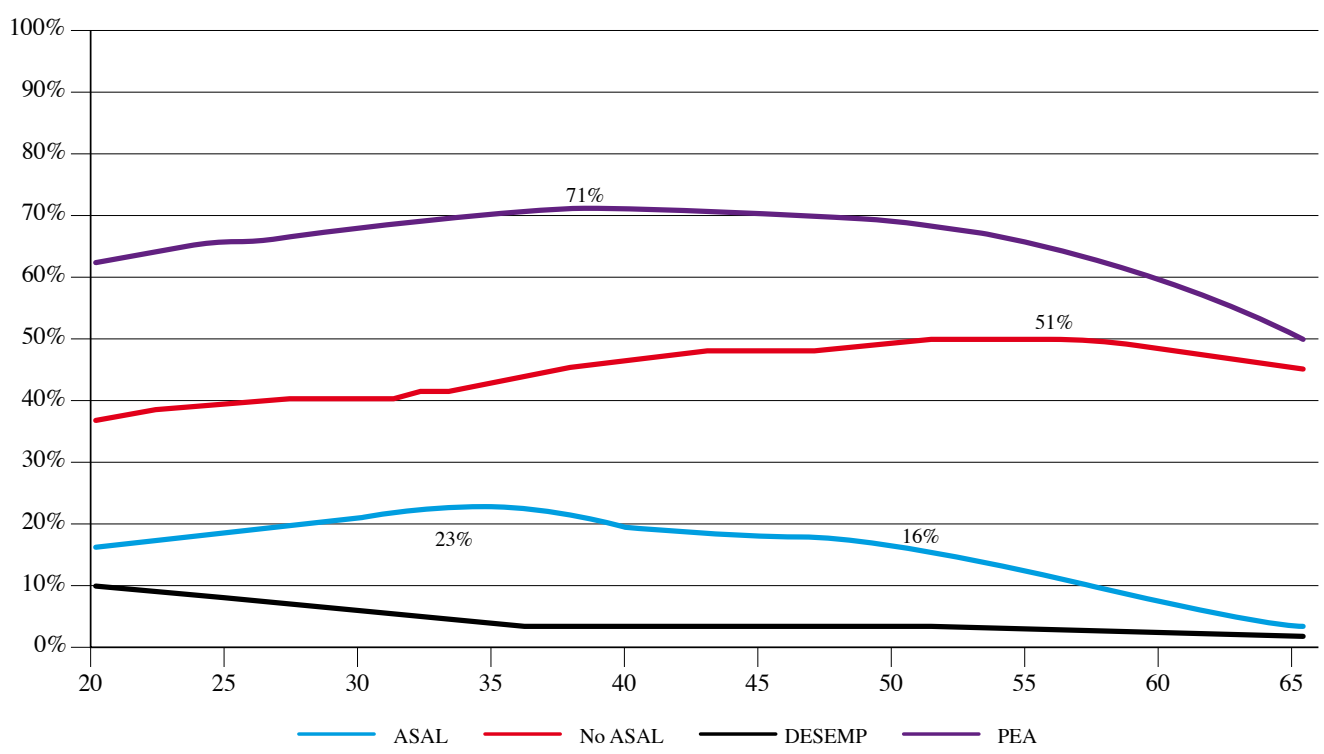

Fuente: López y Lasso (s. f.).

De igual manera, en la figura 3 se evidencia el impacto de la informalidad y la demografía, donde la población económicamente activa tiende a contribuir menos al sistema producto del reemplazo de la mano de obra por tecnología y el estancamiento en la dinámica laboral en cuanto a creación de nuevas plazas de empleo que, en últimas, se traduce en menores aportes a la población en edad de retiro, lo que exige al Estado recursos de su producción interna para solventar estos descalces.

Dadas las tendencias laborales y las cotizaciones, se requiere una mayor eficiencia en la administración de este tipo de recursos por parte de los fondos de pensiones, puntalmente en términos de rentabilidad, ya que de existir rendimientos significativos sobre recursos a largo plazo el pasivo pensional como servicio del PIB puede llegar a reducirse, esto como complemento de los avances logrados en las reformas realizadas; al respecto, puede observarse una importante reducción de 21 puntos básicos desde el Acto Legislativo de 2005, lo que permitirá al Gobierno central liberar recursos para enfocarse en otro tipo de políticas que requieran atención (figura 4). 
Figura 3: Informalidad y demografía

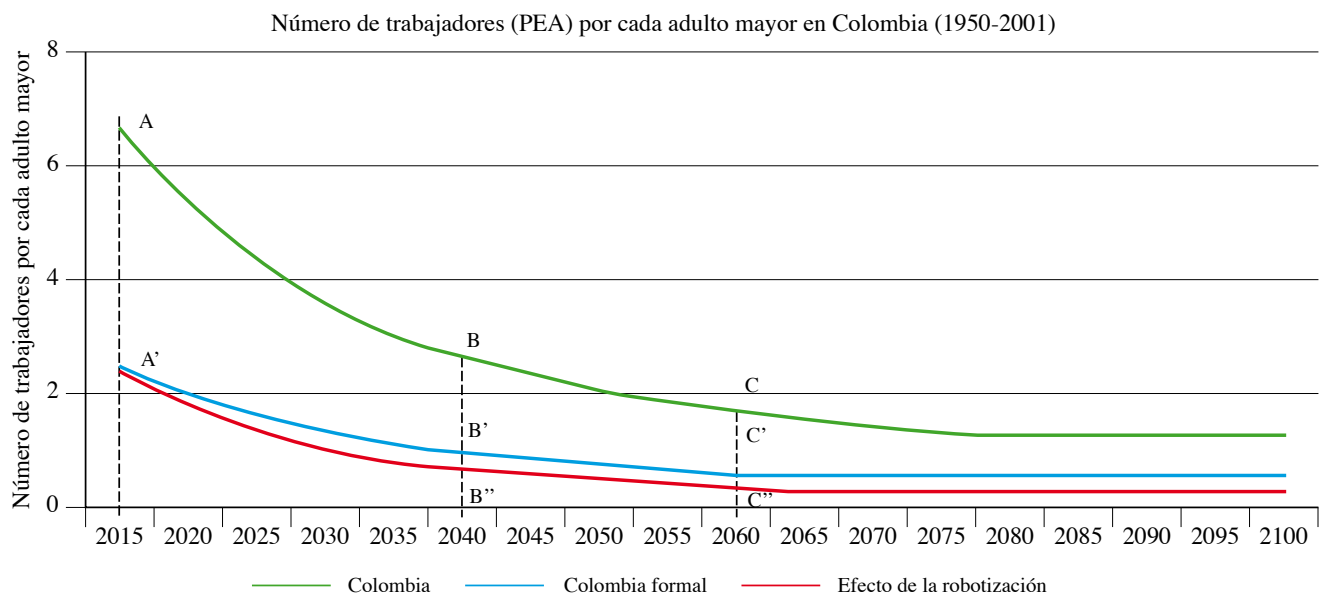

Fuente: Asofondos, Seminario ANIF, noviembre de 2019.

Figura 4: Deuda pensional

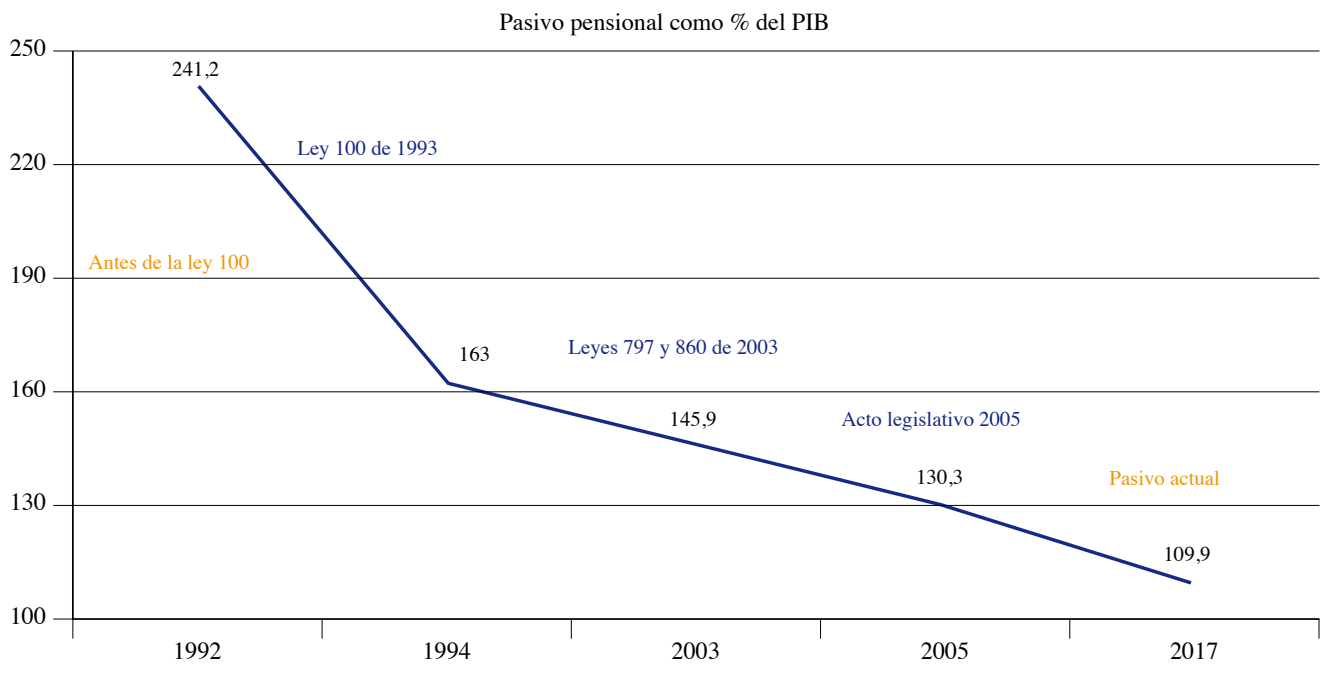

Fuente: Asofondos, Seminario ANIF, noviembre de 2019.

No obstante lo anterior, no todas las decisiones normativas han impactado positivamente a las administradoras de fondos de pensiones colombianas, al respecto se encuentra la Ley 1328 de 2009, conocida como la Ley de Reforma Financiera, la cual introdujo el esquema de multifondos y, según datos de la 
Asociación Colombiana de Administradoras de Fondos de Pensiones y de Cesantía (Asofondos), desde su implementación en 2011 han obtenido una rentabilidad histórica real del $8 \%$, lo que ha permitido que los ahorros de los trabajadores afiliados asciendan a 237 billones, de los cuales el $61 \%$ los representan las rentabilidades obtenidas por las gestiones de los fondos y el $39 \%$ restantes corresponde a aportes de trabajadores y empleadores.

La referida ley, en su artículo 52, consagra la obligatoriedad de las sociedades administradoras de fondos de pensiones y de cesantías de garantizar a los afiliados una rentabilidad mínima para cada uno de los tipos de fondos de pensiones obligatorias (FPO) y portafolios de los fondos de cesantías, la cual es determinada por el Gobierno nacional; en este sentido, los artículos 2.6.5.1.5 y 2.6.9.1.5 del Decreto 2555 de 2010 fijaron que el cumplimiento de la rentabilidad mínima obligatoria para cada uno de los tipos de fondos será verificado mensualmente por la Superintendencia Financiera de Colombia (SFC).

En este sentido, el artículo 2.6.5.1.2 del Decreto 2555 de 2010 establece la metodología para el cálculo de rentabilidad mínima obligatoria de los fondos de pensiones, el cual corresponde a: i) portafolio de referencia; ii) promedio ponderado de las rentabilidades acumuladas efectivas anuales para cada tipo de fondo de pensiones obligatorias. Las ponderaciones del portafolio de referencia varían según el tipo de portafolio: conservador equivale al $30 \%$; moderado al $20 \%$ y riesgoso al $10 \%$. Finalmente, los rendimientos históricos obligatorios (RMO) para cada uno de los fondos administrados será la resultante de la menor de las opciones (tabla 1).

Tabla 1: Cálculo RMO

\begin{tabular}{|l|l|l|}
\hline \multicolumn{1}{|c|}{$\begin{array}{c}\text { Tipo de fondo de } \\
\text { pensiones obligatorias }\end{array}$} & \multicolumn{1}{|c|}{ Opción A } & \multicolumn{1}{c|}{ Opción B } \\
\hline Fondo Conservador & $\begin{array}{l}\text { La suma de los factores ponderados, } \\
\text { disminuidos en un 30\% }\end{array}$ & $\begin{array}{l}\text { La suma de los factores ponderados, } \\
\text { menos 200 puntos básicos }\end{array}$ \\
\hline Fondo Moderado & $\begin{array}{l}\text { La suma de los factores ponderados, } \\
\text { disminuidos en un 35\% }\end{array}$ & $\begin{array}{l}\text { La suma de los factores ponderados, } \\
\text { menos 300 puntos básicos }\end{array}$ \\
\hline Fondo de Mayor Riesgo & $\begin{array}{l}\text { La suma de los factores ponderados, } \\
\text { disminuidos en un 40\% }\end{array}$ & $\begin{array}{l}\text { La suma de los factores ponderados, } \\
\text { menos 400 puntos básicos }\end{array}$ \\
\hline
\end{tabular}

Fuente: Decreto 2555 de 2010, artículo 2.6.5.1.2. 
La obligatoriedad de una rentabilidad mínima puede generar en los administradores de los fondos pensionales la selección de portafolios similares marcados por mayor participación en activos locales que en últimas deriva en niveles de diversificación subóptimos (en sentido Sharpe), dado que en el mercado de capitales colombiano existe un número reducido de alternativas de inversión (León y Laserna, 2008). Producto de estos limitantes que constituyen políticas coercitivas - mas no de incentivo, ya que se cuenta con una penalidad por no cumplir el rendimiento- interpuestos a las administradoras de fondos de pensiones (AFP), el ejercicio de encontrar óptimos en portafolio queda rezagado.

Al realizar el ejercicio práctico de la composición de los portafolios de las diferentes AFP se evidencia el sesgo por inversión en el mercado local (home bias) por la percepción de mayores riesgos en mercados internacionales o restricciones de tipo regulatorio (León y Laserna, 2008) (figura 5).

Figura 5: Portafolios

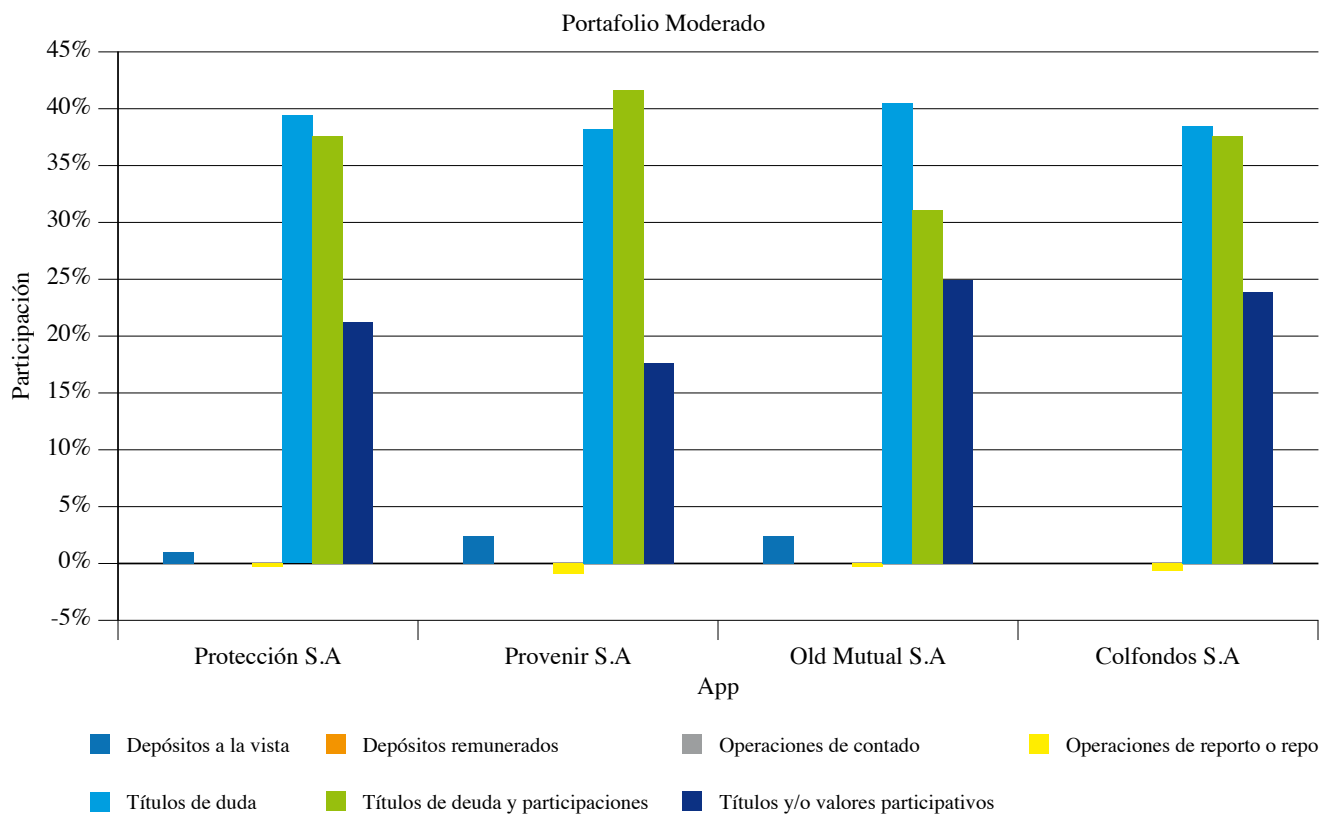



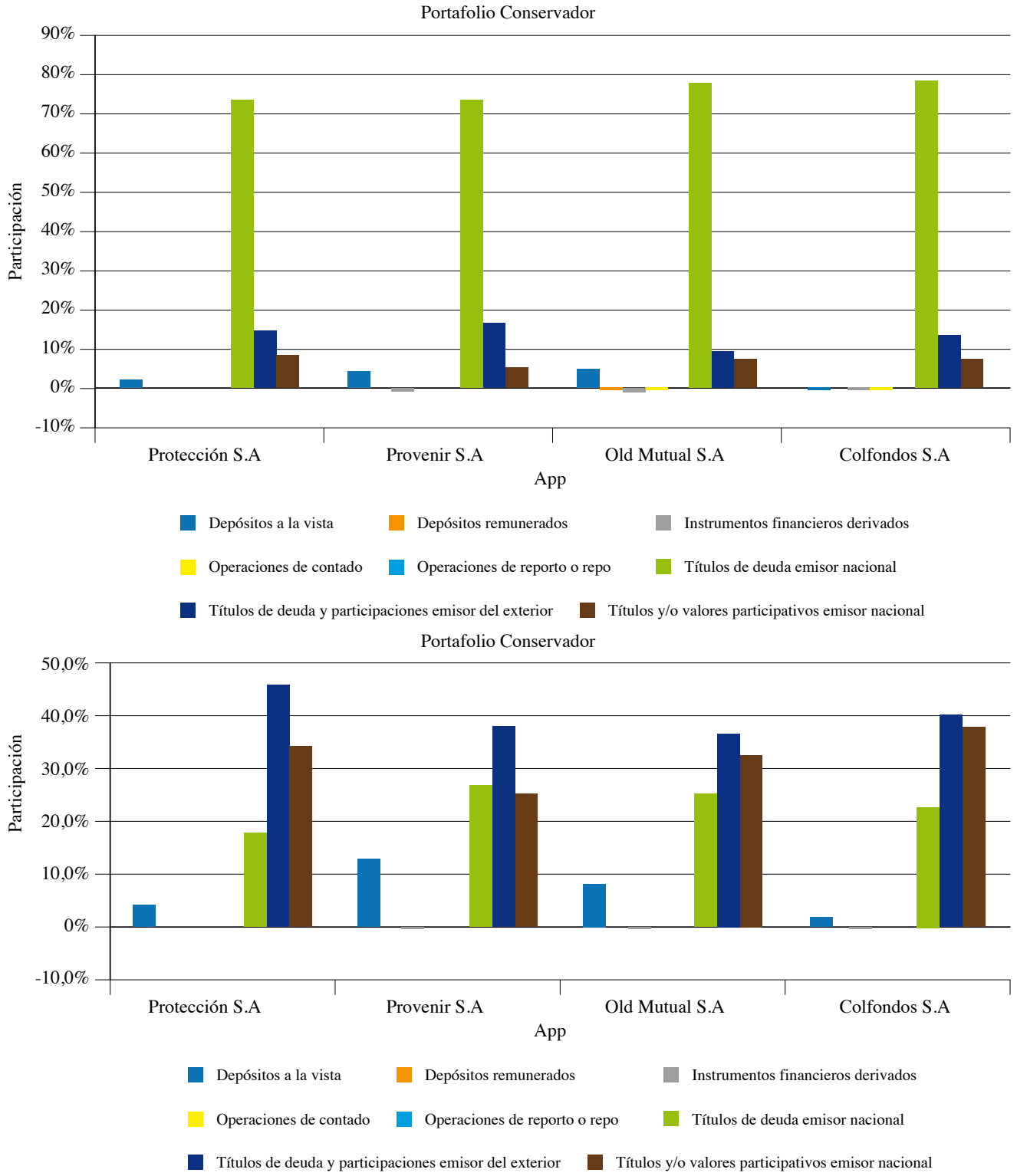

Fuente: cifras Superintendencia Financiera de Colombia (julio 2019). Elaboración propia.

Respecto de la composición de los portafolios, los aspectos regulatorios establecen dos restricciones relacionadas directamente con las inversiones admisibles y los límites establecidos por instrumento y emisor, lo cual nos invita a pensar que estas disposiciones provistas para la protección del ahorro del trabajador 
colombiano terminan por influenciar la eficiencia con la cual se estructure el portafolio en sentido Markowitz, es decir, media-varianza (tabla 2).

Tabla 2: Inversiones admisibles multifondos

\begin{tabular}{|l|c|c|c|}
\hline \multicolumn{1}{|c|}{ Tipos de inversión } & \multicolumn{2}{c|}{ Límite máximo\% } \\
\hline & $\begin{array}{c}\text { Fondo } \\
\text { Conservador }\end{array}$ & $\begin{array}{c}\text { Fondo } \\
\text { Moderado }\end{array}$ & $\begin{array}{c}\text { Fondo } \\
\text { Agresivo }\end{array}$ \\
\hline Títulos de Deuda Pública Interna & 70 & 50 & 50 \\
\hline Carteras colectivas abiertas sin/con pacto de permanencia & 5 & 5 & 5 \\
\hline Carteras colectivas abiertas con pacto de permanencia & 5 & 5 & 5 \\
\hline $\begin{array}{l}\text { Títulos de renta fija emitidos, aceptados o garantizados por } \\
\text { instituciones vigiladas por la SFC }\end{array}$ & 30 & 30 & 30 \\
\hline $\begin{array}{l}\text { Títulos de renta fija emitidos por instituciones no vigiladas } \\
\text { por la SFC }\end{array}$ & 60 & 60 & 60 \\
\hline Títulos de renta variable & 15 & 30 & 45 \\
\hline Títulos emitidos, avalados o garantizados por Fogafín y Fogacoop & 30 & 30 & 30 \\
\hline Títulos de deuda pública externa & 40 & 60 & 30 \\
\hline $\begin{array}{l}\text { Inversiones en títulos emitidos por entidades del exterior, in- } \\
\text { cluyendo títulos de deuda pública, participaciones en fondos } \\
\text { representativos de índices de commodities, de acciones, incluidos } \\
\text { los ETF (Exchange Trade Funds), entre otros }\end{array}$ & 40 & 60 & 70 \\
\hline
\end{tabular}

Fuente: Superintendencia Financiera (2019).

De conformidad con lo expuesto, la presente investigación pretende evaluar una alternativa técnica que, a la luz de las diversas restricciones de orden normativo interpuestas a las AFP colombianas, pueda ser aplicable de manera tal, que se les garanticen selecciones de portafolios eficientes y competitivos que desestimulen el seguimiento estricto de lograr la rentabilidad mínima, la cual no es más que un incentivo a la suboptimización en el sentido riesgo-retorno en los diferentes fondos de pensiones colombianos.

El presente documento se organiza en cinco partes: inicialmente, se señalan investigaciones relacionadas con la problemática expuesta en el presente apartado, seguido de las teorías en torno a la estructuración de portafolio y Support Vector Regression; posteriormente, se señalan los análisis y resultados frente a la data utilizada; en la cuarta sección se presentan las conclusiones y, finalmente, se realizan recomendaciones en torno a futuras investigaciones relacionadas. 


\section{Estructuración de portafolios pensionales colombianos}

Existen varios trabajos que han dado una mirada hacia la problemática de la eficiencia de la estructuración y el balanceo de los portafolios pensionales, entre ellos el de Restrepo, Amezquita y Jara (2005), "Analisis de eficiencia de los portafolios pensionales obligatorios en Colombia", el cual reconoce el problema en el que se encuentran las administradoras de fondos pensionales tras reconocidas reformas como la Ley 100 de 1993, que básicamente es el de composición óptima de portafolio a la cual deben añadirse las restricciones de tipo regulatorio tal como las inversiones admisibles y la rentabilidad mínima obligatoria.

El objetivo del estudio planteado por Restrepo et al. (2005) es generar la frontera eficiente del universo de activos dado; considerando las restricciones regulatorias a las que se enfrentan los fondos de pensiones, se procede a estructurar un portafolio con ciertos activos que representan las inversiones admisibles; de igual manera, se cumplen las restricciones de topes de inversión desde la imposibilidad de posiciones en corto, así como los máximos establecidos. Al definir el horizonte de tiempo, se contempla que no puede rebalancearse el portafolio antes del horizonte de inversión, el cual permite minimizar la incertidumbre inherente a estimaciones de valores esperados de plazos mayores, bajo la premisa de que el comovimiento futuro de los retornos de los activos utilizados está basado en su comovimiento pasado; se establece así la matriz de varianzas y covarianzas histórica.

Los resultados del estudio establecen que los fondos de pensiones privados se ubican un punto porcentual bajo la frontera de eficiencia, contemplando las restricciones regulatorias. Los autores calculan esa ineficiencia en \$280 mil millones que hacen referencia a los rendimientos esperados dejados de percibir; los resultados se plasman en la figura 6 .

Una serie de conclusiones que permite el ejercicio realizado por Restrepo et al. (2005) es que la relación riesgo-retorno desde el ratio de Sharpe se encuentra por el orden de unos 14 puntos porcentuales, superior al portafolio más eficiente del conglomerado de los fondos; también, el fondo mayor tomador de riesgo es ineficiente bajo la razón Sharpe. En el plano de media varianza los fondos de pensiones se ubican a niveles similares de riesgo y retorno esperado, lo que supone un efecto manada a raíz de la exigibilidad de un rendimiento mínimo. 
Figura 6: Fronteras eficientes

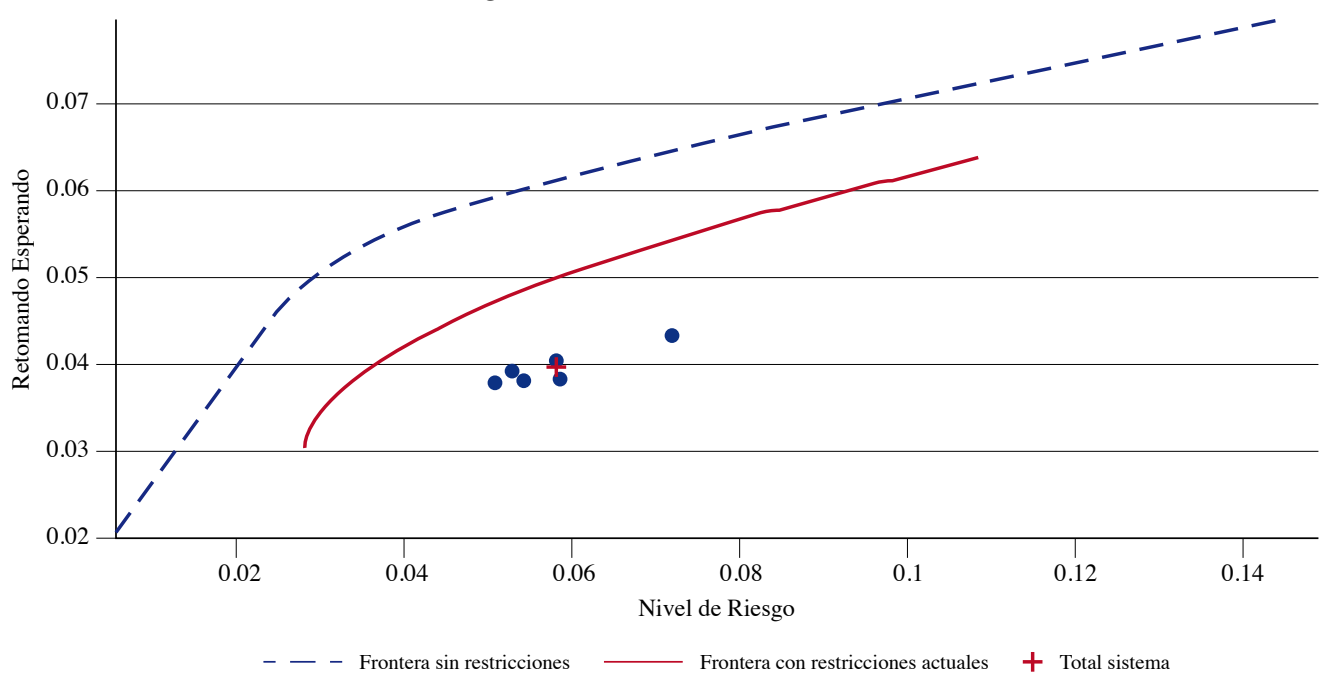

Fuente: Restrepo, Amezquita y Jara (2005).

Otro ejercicio importante realizado por los autores y que permite resultados concluyentes es el análisis de los fondos de pensiones voluntarias que, al parecer, son aún más ineficientes y de lo cual debe tomarse en consideración que estos no cuentan con las restricciones de los administradores de pensiones obligatorias.

Otro texto interesante que enfatiza en un enfoque alternativo a la optimización de portafolio mediante la aplicación el modelo de retorno total-máximo drawdown, que procura un mejor resultado del portafolio de largo plazo como el de los fondos de pensión obligatorias, se expone en Borradores de Economía 523 de 2008.

En el texto se reconoce la importancia de la gestión del administrador de recursos de los aportantes como determinante de los beneficios pensionales futuros y la capacidad del sistema para su subsistencia, o la necesidad de intervención estatal como garante de una pensión mínima a la población colombiana.

Los autores propenden por el uso del criterio retorno total-máximo drawdown como una aproximación a la asignación estratégica de activos para los fondos de pensiones obligatorias, además, se evitan las falencias que presenta el modelo clásico de Markowitz; la principal crítica a este modelo tiene que ver con la diversificación la cual, al contemplar la información extraída en momentos de auge y caída de mercados, que son más breves pero más abruptos, puede sobrevalorar los beneficios de la diversificación y subvalorar el riesgo, ya que no se consideran eventos extremos. 
Producto de lo anterior, y con base en el trabajo realizado por León y Laserna (2008), se desarrolla una metodología que permite minimizar la ocurrencia de eventos negativos extremos y contempla argumentos en contra del modelo de Markowitz; la aplicación de esta metodología en el criterio alternativo de retorno total-máximo drawdown pretende servir de base para la optimización de portafolios en el largo plazo que contemple la asignación estratégica de activos para los FPO en Colombia.

El método consiste en una medición alternativa del riesgo mediante el máximo drawdown (MDD) y retorno total; el MDD radica en la medición de la máxima caída porcentual que le ocurre a una inversión en un periodo de tiempo; de esta forma y entre otros beneficios, el MDD ofrece una optimización de portafolios basada en la minimización de los efectos las discontinuidades y el comportamiento irracional de los mercados; de tal manera que la optimización del portafolio resulta de la combinación de activos que consigue el mínimo MDD para cada nivel de retorno total disponible en el mercado, lo cual deriva en una frontera eficiente.

Así pues, León y Laserna (2008) utilizan series históricas, entre enero de 2000 y diciembre de 2007, de índices de activos representativos de las principales clases de activos existentes; generan veinte portafolios eficientes en el espacio retorno total-máximo drawdown (figura 7).

Figura 7: Frontera eficiente retorno total-MDD

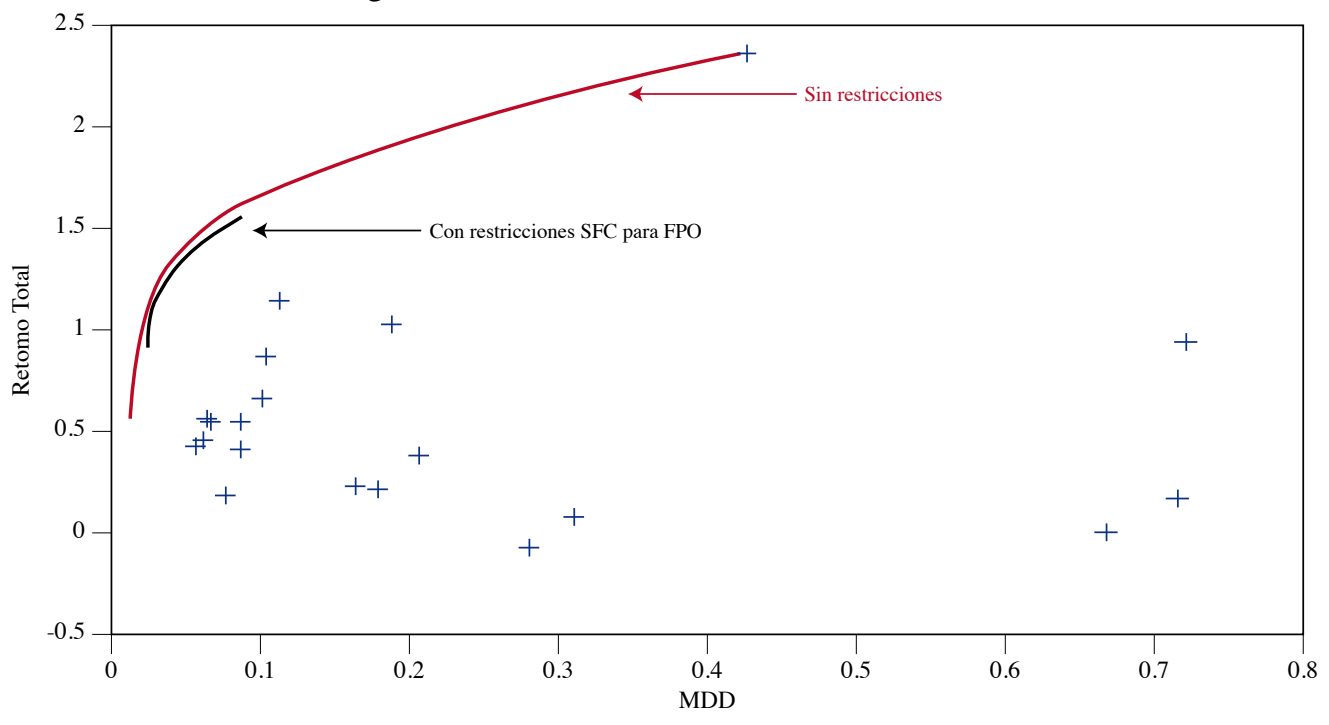

Fuente: León y Laserna (2008). 
León y Laserna (2008) concluyen que con la metodología utilizada se logró un ejercicio consistente en la asignación estratégica de activos para portafolios de largo plazo, tal como lo demandan las distintas FPO y, a su vez, se confirma "la necesidad de una diversificación internacional y de mantener una exposición cambiaria en portafolios de largo plazo así como considerar el impacto de los eventos extremos, para conseguir la maximización de la riqueza de un inversionista interesado en el largo plazo, como lo es un afiliado al sistema pensional".

En cuanto a la estructuración de los portafolios de los fondos pensionales colombianos se encuentra el trabajo realizado por Trujillo Segura (2009), "Construcción y gestión de portafolios con el modelo Black-Litterman: una aplicación a los fondos de pensiones obligatorias en Colombia", donde se busca hacer un análisis detallado de los componentes del modelo Black-Litterman y su aplicación a los fondos de pensiones colombianos.

En este sentido, Fisher Black y Rober Litterman propusieron un modelo para estimar los retornos de los activos que se introducen al optimizador de Markowitz de tal forma que se reduzcan los problemas de la metodología tradicional, el cual se basa en el método bayesiano debido a que proporciona una estructura teórica sólida que combina varias fuentes de información y flexibilidad en el manejo de modelos realistas y complejos donde existen múltiples activos y restricciones, y las ponderaciones óptimas no son tan obvias o intuitivas (Trujillo Segura, 2009).

El objetivo de la asignación estratégica de activos es crear una mezcla de activos estable que maximice los retornos esperados de largo plazo para un nivel de riesgo deseado. La asignación estratégica conlleva la adopción o creación de un índice de referencia y la posterior determinación y monitoreo de las asignaciones del portafolio con respecto a ese índice (Trujillo Segura, 2009). Al crear dicha asignación adicionalmente se están estableciendo las ponderaciones mínimas y máximas para cada clase de activos como mecanismo de control de riesgo.

En un contexto de media-varianza de Markowitz, el problema del inversionista es de minimización restringida definida:

$$
\min _{w} w \sum w
$$

Sujeta a:

$$
\begin{gathered}
\mu^{\prime} w \geq \mu_{0} \\
w^{\prime} i=1, \text { Donde } i^{\prime}=[1,1, \ldots, 1]
\end{gathered}
$$


El análisis de media varianza no está restringido al uso de promedios históricos, sino que puede utilizarse con retornos esperados derivados a partir de cualquier otro método. Se debe tener en cuenta que la utilización eficiente de las técnicas de optimización de media-varianza en un contexto práctico requiere una apreciación de sus limitaciones (Trujillo Segura, 2009).

De tal manera que el autor presenta el modelo Black-Litterman como una alternativa y solución a los problemas de enfoque tradicional de Markowitz para la construcción de portafolios y para hacer más prácticas las herramientas cuantitativas para la asignación de activos; en la figura 8 se resume la metodología de forma gráfica.

Figura 8: Metodología Black-Litterman

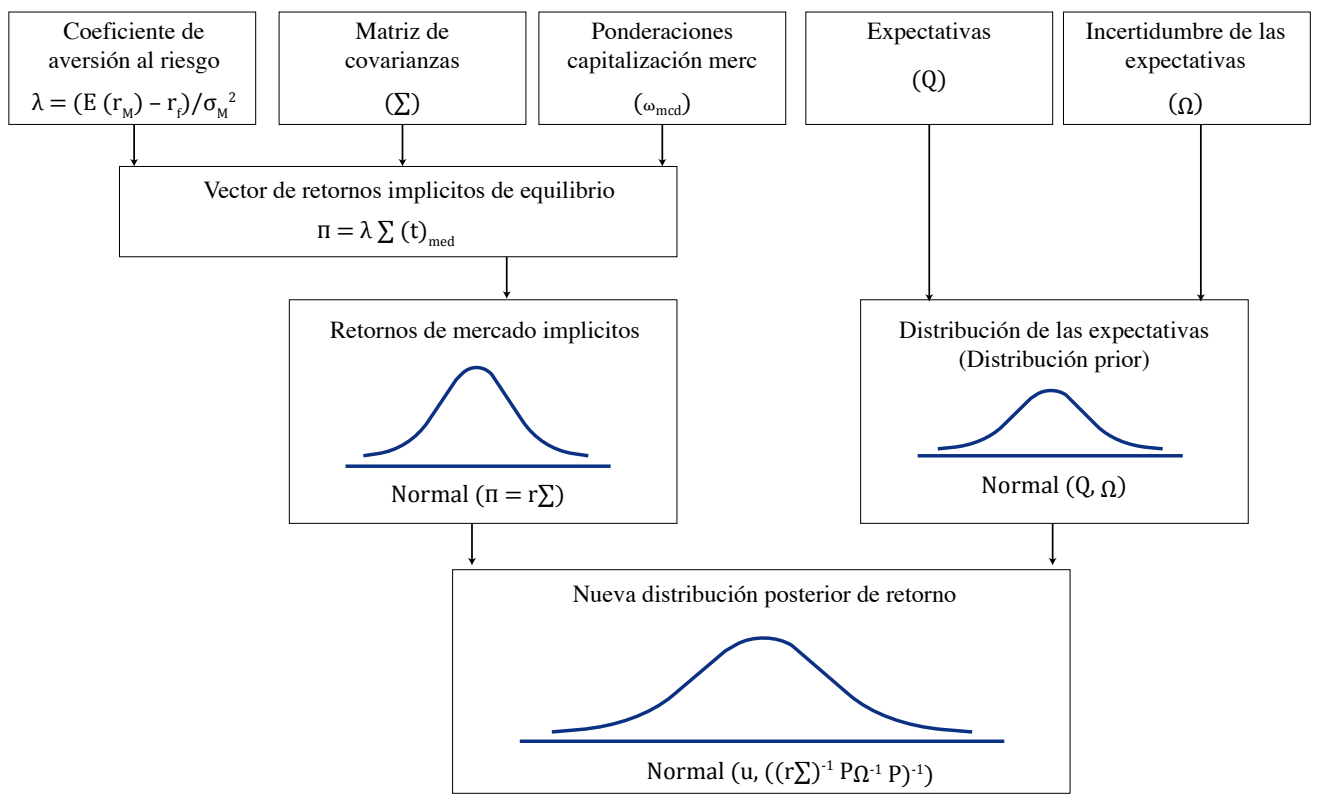

Fuente: Trujillo Segura (2009).

Lo principal en cuanto a los retornos esperados de Black-Litterman es el equilibrio de mercado y la combinación con las expectativas de este según el enfoque bayesiano, para generar la distribución posterior de los retornos esperados $\mu$, la cual es normal con media $\mu_{B L}$ dada por:

$$
\mu_{B L}=\left[(\tau \Sigma)^{-1}+P^{\prime} \Omega^{-1} P\right]^{-1}\left[(\tau \Sigma)^{-1} \Pi+P^{\prime} \Omega^{-1} Q\right]
$$




$$
=\left[(\tau \Sigma)^{-1}+P^{\prime} \Omega^{-1} P\right]^{-1}\left[(\tau \Sigma)^{-1} \Pi+P^{\prime} \Omega^{-1} P \hat{\mu}\right.
$$

Y varianza posterior $\bar{M}^{-1}$ dada por:

$$
\bar{M}^{-1}=\left[(\tau \Sigma)^{-1}+P^{\prime} \Omega^{-1} P\right]^{-1}
$$

Donde $\hat{\mu}$ es el valor estimado de los retornos esperados implícitos en las opiniones, es decir $\hat{\mu}=\left(P^{\prime} P\right)^{-1} P^{\prime} Q$. Enfocándose en la expresión del segundo conjunto de paréntesis cuadrados, se puede observar que el modelo Black-Litterman es un simple promedio ponderado del equilibrio de mercado, $\prod$, y el retorno esperado implícito en las opiniones del inversionista, $\hat{\mu}$, con las ponderaciones iguales a:

$$
\begin{gathered}
w_{\Pi}=\left[(\tau \Sigma)^{-1}+P^{\prime} \Omega^{-1} P\right]^{-1}(\tau \Sigma)^{-1} \\
w_{Q}=\left[(\tau \Sigma)^{-1}+P^{\prime} \Omega^{-1} P\right]^{-1} P^{\prime} \Omega^{-1} P
\end{gathered}
$$

Donde, $w_{\Pi}+w_{Q}=I$

Es decir que las ponderaciones relativas están determinadas por el grado percibido de dispersión en los retornos esperados de equilibrio y la confianza en las expectativas, respectivamente.

Debido a que los retornos de los activos están correlacionados, opiniones sobre unos cuantos activos implicarán cambios en los retornos esperados de todos los activos. En efecto $P^{\prime} \Omega^{-1}$ es una matriz $N x K$ que propaga las $\mathrm{K}$ opiniones en $\mathrm{N}$ componentes $P^{\prime \Omega-1} Q$ Si no se hiciera este ajuste en el vector de retornos esperados, las diferencias entre los retornos esperados de equilibrio y las opiniones del inversionista serían interpretadas como oportunidades de arbitraje por el optimizador, lo que conduciría a portafolios concentrados en unos cuantos activos. En términos intuitivos, cualquier error de estimación se dispersa entre todos los activos, lo cual hace que los retornos de Black-Litterman sean menos sensibles a los errores de opiniones individuales (Trujillo Segura, 2009).

En los términos de Trujillo Segura (2009), el modelo permite al administrador de portafolios incluir sus expectativas de mercado y, ante el arribo de nueva información, actualizarlas. A diferencia del modelo estándar, el de Black-Litterman no requiere que los retornos esperados de cada activo sean estimados. Solo es 
necesario que el inversionista provea un retorno esperado para aquellos activos sobre los que tiene una opinión valiosa. Esto es más congruente con la práctica debido a que es muy difícil que el administrador tenga un conocimiento detallado o una expectativa significativa sobre cada uno de los activos en el portafolio. Además, hay muchos grados de libertad en la implementación del modelo; comúnmente es utilizado de forma iterativa hasta que el inversionista siente que ha logrado obtener el balance apropiado en el portafolio. Esta flexibilidad es la que hace el modelo tan atractivo a diferentes inversionistas en distintas situaciones.

Adicionalmente, la metodología produce portafolios más balanceados y estables en el tiempo al utilizar los retornos del equilibrio como centro de gravedad; la solución está anclada en el reconocido portafolio del mercado. En consecuencia, la necesidad de rotar el portafolio y los costos de transacción es menor (Trujillo Segura, 2009).

En términos de Trujillo Segura (2009), a diferencia del enfoque tradicional, el modelo Black-Litterman produce portafolios más diversificados a lo largo de la frontera eficiente, al mismo tiempo que incorpora las expectativas del administrador del fondo produciendo portafolios más intuitivos.

El principal aporte del modelo de Markowitz para la selección de un portafolio óptimo se encuentra en su utilidad para recoger los aspectos fundamentales que deben guiar a un inversionista racional en la elección de la composición de su portafolio, de tal forma que le produzca la máxima rentabilidad, al controlar el riesgo; o en forma alternativa, minimizar el riesgo, controlando el rendimiento (Franco, Avendaño y Barbutín, 2011).

La principal ventaja del modelo Black-Litterman frente al modelo de Markowitz es que permite incluir las expectativas del inversor y, de acuerdo con la confianza que se maneja sobre las mismas, se da un mayor o menor peso al activo dentro del portafolio. El modelo Black-Litterman es favorable principalmente para administradores que siempre están buscando buenas estrategias y que estudian y revisan constantemente el comportamiento del mercado (Franco et al., 2011).

\section{Teorías relacionadas}

\subsection{Ratio de Sharpe}

Se puede decir que uno de los pilares fundamentales en las teorías de la selección de portafolios es la relación entre el retorno esperado y la varianza, entendiendo a esta última como riesgo. El trabajo realizado por Sharpe (1966) en "Mutual 
fund performance" enfatiza en que la selección de una combinación preferente de riesgo y retorno depende fundamentalmente del inversionista y no debería solo depender de los técnicos; sin embargo, estos pueden procurar la búsqueda de un portafolio eficiente en donde los analistas, en general, tienen la responsabilidad de traducir predicciones de rendimientos sobre títulos en predicciones de rendimientos sobre portafolios y elegir entre un gran número de portafolios los que son eficientes. Por su parte, el inversionista se preocupa por seleccionar de una cantidad de portafolios eficientes aquel que según su preferencia sea más deseable conforme al riesgo y el retorno esperado.

Desde esta perspectiva, y en los términos de Sharpe, el fondo de inversión enfatiza en la diversificación, y la búsqueda de precios de valores no correlacionados refleja la importancia conforme los aspectos del proceso analítico desde los activos y desde el rendimiento del portafolio. Los fondos de inversión no pueden determinar las preferencias particulares de los inversionistas dadas las diferencias sustanciales entre ellos, de tal forma que el método debe ir en la perspectiva del fondo de manera que el administrador de este asuma una posición frente a riesgo y rentabilidad esperada y, posteriormente, se invite a participar a los inversionistas con preferencias similares.

De tal modo que Sharpe asume que los rendimientos ex post de los fondos de inversión pueden ser vistos desde dos aspectos: diferentes fondos podrían mostrar distintos grados de variabilidad en retornos ya sea por la selección consciente de diferentes grados de riesgos o predicciones erróneas de riesgos inherentes en portafolios particulares. $\mathrm{O}$, fondos tenedores de portafolios con variabilidad similar en los retornos podrían mostrar mejores diferencias en retornos promedio debido a la incapacidad de algunos administradores para seleccionar de manera adecuada los títulos indicados o la diversificación propiamente hablando (Sharpe, 1966).

Estos aspectos, sumados a las teorías de caminata aleatoria en relación con el comportamiento pasado de los precios de los activos, no tienen ningún valor respecto a la predicción de su precio futuro; adicionalmente, la rápida incorporación de la información en el precio de los activos puede suponer la existencia de un mercado perfectamente informado, en donde cada participante usa la información sugerida por la teoría de análisis de portafolio.

De esta manera, el rendimiento esperado puede ser medido de dos maneras: la tasa de retorno esperada $\left(E_{j}\right)$ y la variabilidad prevista o riesgo, la cual se expresa como la desviación estándar de los rendimientos $\left(\sigma_{i}\right)$. Todos los inversionistas están dispuestos a realizar inversiones en fondos comunes con tasas libres de 
riesgo y conceder préstamos a la misma tasa; en algún punto del tiempo, todos los inversionistas comparten la misma predicción sobre los rendimientos esperados, por consiguiente, todos los portafolios eficientes estarían ubicados en la recta

$$
E_{i}=p+b \sigma_{i}
$$

Donde $p$, es la tasa libre de riesgo y $b$ es la prima por riesgo; cuando el inversionista sea adverso al riesgo la variable $b$ tomará valores positivos. Siguiendo con la presunción de que el inversionista puede prestar o pedir prestado a la tasa libre de riesgo $p$ o invertir en un portafolio con rendimiento esperado $\left(E_{i}\right.$, $\sigma_{i}$ ), él puede ubicar el fondo entre el portafolio y los préstamos o prestamistas y puede lograr un punto en la línea

$$
E=p+\left(\frac{E_{i}-p}{\sigma_{i}}\right) \sigma
$$

Por tanto, dará lugar a una completa frontera lineal de combinaciones de $E, \sigma$; el mejor portafolio estará en la frontera y será el de mayor ratio $\left(E_{i}-P\right) / \sigma_{i}$. Si más de un portafolio es eficiente, todos deben estar a lo largo de la línea y tener resultados comunes para esta ratio (Sharpe, 1966).

Con estas importantísimas aportaciones de Sharpe a la relación riesgorendimiento y la construcción de una línea de mercado, en su trabajo "Mutual Fund Performance" se realizó un análisis de 34 fondos de inversión abiertos y cerrados en los periodos 1954-63, donde se resalta que la tasa anual de retornos se determinó por la suma de dividendos pagados, la distribución de capital y la variación neta del valor de los activos. Lo que logra evidenciar Sharpe del análisis de los fondos es que la relación predicha por la teoría capital assets prices es claramente demostrable; los portafolios con grandes retornos promedios típicamente muestran mayor variabilidad en comparación con los de pequeños rendimientos.

\subsection{Media varianza Markowitz}

Mark Rubistein, en su artículo "Markowitz's Portfolio Selection: A fifty-year retrospective", considera la publicación de Portfolio Selection como el nacimiento de la economía financiera moderna, aunque no fue precisamente el 
primero en hablar de los beneficios de la diversificación, ya que previamente lo hizo Bernulli en la Paradoja de San Petersburgo (1738); de otra parte, la varianza puede ser atribuida a Irving Fisher en The Nature of Capital and Income (1906); a su vez, Jacob Marschak (1938) sugirió utilizar la media y matriz de covarianza del consumo de mercancías como aproximación de primer orden a la medición de la utilidad.

Markowitz tuvo la brillante idea de que si bien la diversificación reducía el riesgo en general, no lo eliminaría convirtiéndose en la primera formalización matemática de la idea de diversificación en inversión (Rubinstein, 2010); Markowitz postula además que un inversor debería maximizar el rendimiento esperado de la cartera $\mu_{P}$ mientras se optimiza la varianza de la cartera $\sigma_{P}^{2}$ en términos de Rubinstein; el aspecto más importante del trabajo de Markowitz fue mostrar que no es el riesgo de un activo lo más importante para el inversionista, sino más bien la varianza de todo su portafolio, esto se deduce de la relación de la varianza del rendimiento de la cartera y la varianza del rendimiento de sus $\operatorname{activos} \sigma_{P}^{2}=\sum_{j} x_{j}^{1} \sigma_{j}^{2}+\sum_{R \neq j} x_{j} x_{R} \sigma_{j R} \sigma_{j} \sigma_{R}$ :

$$
\sigma_{P}^{2}=\sum_{j} x_{j}^{1} \sigma_{j}^{2}+\sum_{R \neq j} x_{j} x_{R} \sigma_{j R} \sigma_{j} \sigma_{R}
$$

Donde $x_{j}$ son las proporciones del portafolio y $\sigma_{j R}$ es la correlación de los retornos de los activos $j, R$, por tanto, $\sigma_{j R} \sigma_{j} \sigma_{R}$ es la covarianza de esos retornos. La decisión de mantener un activo no debe basarse solamente en su valor esperado y la varianza respecto de otros, sino que esta dependerá de los otros activos, en consecuencia, los activos no deben evaluarse de forma aislada sino en conjunto (Rubinstein, 2006; 2010).

El mejor trabajo de teoría de portafolio de la década de los cincuenta, después de la publicación del libro de Markowitz, fue realizado por el mismo en su texto de 1959, Portfolio Selection, donde proporciona un extenso y detallado desarrollo del modelo de selección de portafolio media-varianza; en vista de trabajos recientes de von Neuma y Morgenstern (1947) y Savage (1954), Markowitz también se esforzó por encontrar una manera de conciliar su criterio de varianza con la maximización de la utilidad esperada de la riqueza para muchos periodos de reinversión (Rubinstein, 2010).

En Pfaff (2016), al igual que en Rubinstein (2010) se considera un portafolio eficiente si tiene un riesgo mínimo para un nivel de rendimiento determinado, o si tiene un rendimiento máximo para un nivel de riesgo explícito. Aunque ambas 
visiones de portafolios eficientes son similares, el tipo de optimización es diferente, la primera es una optimización cuadrática con restricciones lineales mientras que, en la segunda, la función objetivo es lineal y las restricciones cuadráticas.

A continuación, se supone que hay $N$ activos y son infinitamente divisibles, los rendimientos de estos activos se distribuyen normalmente de manera conjunta, el rendimiento de la cartera $\bar{r}$ se define por el producto escalar (Nx1) los vectores de ponderaciones y retorno $\omega$ y $\mu$, el riesgo de la cartera se mide por la varianza $\sigma_{W}^{2}=\omega^{\Sigma \omega}$, donde $\Sigma$ denota la matriz de varianzas-covarianzas semidefinida positiva de los rendimientos de los activos. Para el caso de portafolio de mínima varianza para un rendimiento de cartera dado, $\bar{r}$, el problema de optimización puede expresarse como:

$$
\begin{gathered}
P=\arg \min _{\omega} \sigma_{W}^{2}=\omega^{\prime} \sum \omega \\
\omega^{\prime} \mu=\bar{r}, \omega^{\prime} i=1 \text {. Dónde } i \text { es }(N x 1) \text { vector de unos }
\end{gathered}
$$

En el mismo año en que Markowitz publicó su artículo seminal, Roy (1952) derivó la función para determinar las carteras eficientes, aunque el artículo de Merton (1972) es el más citado; según esta función, el vector de participaciones para un portafolio de mínima varianza y un rendimiento determinado está dado por:

$$
\begin{gathered}
\omega^{*}=\bar{r} \omega_{0}^{*}+\omega_{1}^{*} \operatorname{con}: \omega_{0}^{*}=\frac{1}{d}\left(c \sum^{-1} \mu-b \sum^{-1} i\right) \\
\omega_{1}^{*}=-\frac{1}{d}\left(b \sum^{-1} \mu-a \sum^{-1} i\right)
\end{gathered}
$$

La desviación estándar del portafolio es dada por:

$$
\sigma=\sqrt{\frac{1}{d}}\left(c \bar{r}^{2}-2 b \bar{r}+a\right)
$$

Con $a=\mu^{\prime} \Sigma^{-1} \mu, b=\mu^{\prime} \Sigma^{-1} i, c=\mu^{\prime} \Sigma^{-1} i$ y $d=a c-b^{2}$; de esta ecuación se concluye que las ponderaciones de la cartera son una función lineal de los rendimientos esperados, además, es posible demostrar que cada cartera eficiente se puede generar con una combinación lineal de otras carteras eficientes. En particular, 
el perfil riesgo/retorno de un portafolio eficiente puede expresarse en términos de una combinación lineal entre la cartera de varianza mínima global (GMV) y cualquier otra cartera eficiente; la covarianza entre estas dos carteras es igual a la varianza de la cartera de mínima varianza. Aunque puede no ser evidente a primera vista, debe enfatizarse que la única restricción con respecto a las ponderaciones de las carteras es que su suma debe ser igual a 1, por tanto, ni posiciones cortas ni apalancadas pueden descartarse. La ecuación de la desviación estándar del portafolio describe una hipérbola para portafolios eficientes de media varianza (Pfaff, 2016).

En contraste con el portafolio de media varianza, el vector de ponderaciones de la cartera GMV no depende de los retornos esperados de los activos; las contribuciones marginales al riesgo de los activos contenidos en las carteras eficientes son iguales y los pesos corresponden al porcentaje de las contribuciones al riesgo, por tanto, esos pesos son Pareto eficientes (Pfaff, 2016).

Las carteras incluidas en la hipérbola son subóptimas, dado que existen carteras con rendimientos más altos para un determinado nivel de riesgo o son menos riesgosas para cierto nivel de rendimiento de la cartera.

Al permitir la tenencia de un activo sin riesgo con un retorno $r_{f}$ debe preguntarse qué tan alta debe ser la tenencia óptima en este activo en la cartera, lo que dependerá de la aversión al riesgo del inversor; un inversor reacio al riesgo intenta maximizar su riqueza al final del periodo, por lo que la decisión sobre la forma de la cartera debe tomarse el iniciar de este:

$$
\max E\left[U\left(W^{(t+1)}\right)\right],
$$

donde $E$ denota el operador de expectativas, la función de utilidad se puede aproximar mediante una expansión de la serie Taylor y se supone, además, que esta función es dos veces diferenciable después de una extensión neutral $U\left(W\left(^{t+1)}\right)=U\left(W^{(t+1)}+E\left[W^{(t+1)}\right]-E\left[W^{(t+1)}\right]\right)\right.$; la función de utilidad por ser maximizada se escribe:

$$
\begin{gathered}
E\left[U\left(W_{(t+1)}\right)\right]=U\left(\left[W_{(t+1)}\right]\right)+\frac{U^{\prime}\left(\left[W_{(t+1)}\right]\right)}{1 !} E\left[W_{(t+1)}-E\left[W_{(t+1)}\right]\right] \\
+\frac{U^{\prime \prime}\left(\left[W_{(t+1)}\right]\right)}{2 !} E\left[W_{(t+1)}-E\left[W_{(t+1)}\right]\right]^{2}
\end{gathered}
$$




$$
+\sum_{i=3}^{\infty} \frac{U^{(i)}\left(E\left[W_{(t+1)}\right]\right)}{i !} E\left[W_{(t+1)}-E\left[W_{(t+1)}\right]\right]^{i}
$$

Al suponer que la riqueza se distribuye normalmente, la expresión se simplifica a:

$$
\begin{gathered}
E\left[U\left(W_{(t+1)}\right)\right]=U\left[\left(W_{(t+1)}\right)\right]+\frac{U^{\prime}\left(\left[W_{(t+1)}\right]\right)}{1 !} E\left[W_{(t+1)}-E\left[W_{(t+1)}\right]\right] \\
+\frac{U^{\prime \prime}\left(\left[W_{(t+1)}\right]\right)}{2 !} E\left[W_{(t+1)}-E\left[W_{(t+1)}\right]\right]^{2}
\end{gathered}
$$

Por tanto, la utilidad del inversor solo depende de los primeros dos momentos; cabe destacar que incluso en el caso de no normalidad, el enfoque de optimización anterior se puede utilizar para funciones de utilidad cuadráticas de la forma $U(W)=W-\frac{\lambda}{2} W^{2}$, el parámetro $\lambda$ es la medida de aversión al riesgo del inversionista (Pfaff, 2016).

Si se asume función de utilidad cuadrática, entonces el vector de pesos está dado por $\omega_{U}=(1 / \lambda) \Sigma^{-1} \mu$, cuanto mayor es la aversión al riesgo, menor es la suma de los pesos; el retorno esperado $\mathrm{R}$ de los activos riesgosos y el libre de riesgo viene dado por:

$$
\begin{gathered}
E[R]=(1-\gamma) r_{f}+\gamma \bar{r} \\
=r_{f}+\gamma\left(\bar{r}-r_{f}\right)
\end{gathered}
$$

Donde $\gamma=i^{\prime} \omega$ es la participación de activos de riesgo en comparación con la riqueza total; la desviación estándar del portafolio es $\sigma(R)=\gamma \sigma_{W}$, a partir de esto, la línea de mercado de capitales puede derivarse en una relación lineal en el plano $(\sigma, \mu)$ :

$$
E[R]=r f+\frac{\bar{r}-r f}{\sigma_{W}} \sigma(R)
$$


La cartera óptima se encuentra en el punto de tangencia de esta línea y la rama superior de la frontera eficiente, esto se da cuando la pendiente es mayor y, por tanto, la relación de Sharpe está en su máximo. La cartera, en este punto de tangencia, también se conoce como cartera de relación máxima de Sharpe (MSR); en el caso de la cartera de MSR, el inversor solo posee activos riesgosos. Las contribuciones marginales de los activos seleccionados a la relación de Sharpe son todas iguales, de esta manera, el grado de inversión está determinado por el punto de tangencia de su función de utilidad y la CML. Este punto se encuentra al suroeste de la cartera de MSR, y cuanto mayor sea la aversión al riesgo, más cerca se ubicará de la ordenada (Pfaff, 2016).

\subsection{Black-Litterman Model}

En el artículo de Idzorek, "A step-by-step guide to the Black-Litterman model" (2007), sostiene que el modelo de asignación de activos desarrollado por Black-Litterman constituye un sofisticado método de asignación de activo que supera con creces al de media-varianza, el cual considera de difícil aplicación dado los problemas de alta concentración de portafolios, poco intuitivo, sensibilidad y errores de estimación.

Por su parte, el modelo Black-Litterman usa aproximaciones bayesianas para combinar las opiniones subjetivas de los inversionistas respecto de los rendimientos esperados de uno o más activos en el vector de rendimientos de equilibrio (distribución prior), para formar una nueva estimación mixta de los rendimientos esperados, un nuevo vector resultante de retornos (distribución posterior), lo que conduce a carteras intuitivas y con pesos razonables (Idzorek, 2007).

El modelo usa los retornos de equilibrio como un punto neutral de partida, estos se derivan utilizando un método de optimización inversa en el que del vector de excesos de retorno implícitos se extrae de la información conocida mediante la ecuación:

$$
\Pi=\lambda \Sigma \omega_{m k t}
$$

donde:

$\Pi$ : vector de retornos de equilibrio implícitos $(N \times 1)$.

$\lambda$ : coeficiente de aversión. 
$\Sigma$ : matriz de covarianzas de los excesos de retorno (matriz $N \times N$ ).

$\omega_{m k t}$ : ponderación de activos de mercado (vector columna $N \times 1$ ).

El coeficiente de aversión caracteriza la compensación por riesgo, es la tasa a la que un inversor renunciará al rendimiento esperado por menor variación (Idzorek, 2007).

Una apreciación de Idzorek frente a la estimación de los retornos es el uso del capital asset pricing model (CAPM) -el cual, al ser calculado con las ponderaciones relativas del mercado y mediante los betas implícitos, resulta en los retornos de equilibrio $\Pi-$; Idzorek afirma que, con frecuencia, en la literatura Black-Litterman se refiere al vector de retornos implícito como retornos de CAPM, lo cual puede ser confuso; retornos de CAPM basados en regresiones beta pueden diferir de forma significativa en los retornos CAPM basados en betas implícitos. Los betas implícitos son los betas de los $\mathrm{N}$ activos en relación con las ponderaciones de las carteras de mercado:

$$
\beta=\frac{\sum \omega_{m k t}}{\omega_{m k t}^{T} \sum \omega_{m k t}}=\frac{\sum \omega_{m k t}}{\sigma^{2}}
$$

donde:

$\beta$ : vector de betas implícito.

$\Sigma$ : matriz de covarianzas de excesos de retorno.

$\omega_{m k t}:$ ponderaciones del mercado.

$\sigma^{2}=\omega_{m k t}^{T} \sum \omega_{m k t}=\frac{1}{\beta^{T} \sum^{-1} \beta}$ : varianza de los excesos de retorno del mercado o benchmark.

De otra parte, se sostiene que uno de los aspectos más confusos del modelo son los inputs de los views. Primero que todo, el modelo no requiere que los inversionistas definan views sobre todos los activos, la incertidumbre de los views da como resultado un término de error aleatorio, independiente, normalmente 
distribuido $\varepsilon$ con media 0 y matriz de covarianza $\Omega$; los views serán de la forma $Q+\varepsilon$, el término del error no ingresa de forma directa en la fórmula BlackLitterman, sin embargo, la varianza de cada término $\omega$, que es la diferencia absoluta del término de error $\varepsilon$ de valor esperado 0 ingresa a la fórmula. $\mathrm{La}$ varianza del término de error de $\Omega$, es una diagonal de la matriz de covarianzas con todos los demás elementos igual a 0 ya que el modelo asume independencia entre los views (Idzorek, 2007).

Los views de la matriz Q se expresan con activos específicos en la matriz P, de tal manera que $\mathrm{K}$ views resultan en una matriz $K x N$, y una vez esta es definida la varianza de cada view del portafolio puede calcularse, $p_{k} \Sigma p_{k}^{\prime}$, donde $p_{k}$ es el vector fila $1 \mathrm{x} \mathrm{N}$ de la matriz $\mathrm{P}$ que corresponde a la $k$ th view, y $\Sigma$ es la matriz de covarianza de los excesos de retorno. La varianza de cada una de las vistas es información importante ya que representa el nivel de certeza o confianza respecto de cada view (Idzorek, 2007).

Conceptualmente, el modelo Black-Litterman es una compleja ponderación de los retornos de equilibrio implícitos $\Pi$ y vector de views $\mathrm{Q}$ en que las ponderaciones relativas están en función de un escalar $\tau$ y la incertidumbre de los views $\Omega$; tanto el escalar como la incertidumbre de los views son los parámetros más difíciles de especificar en el modelo, cuanto mayor es el nivel de confianza en los views, más cerca de estos estará el nuevo vector de retornos; entre menor confianza, el nuevo vector deberá estar más cerca del vector de retornos de equilibrio $\Pi$. El escalar $\tau$ es más o menos el peso relativo que se le da al vector $\Pi$.

Debido a que existe escasa literatura respecto al escalar $\tau$, Black-Litterman y Lee establecieron que, dado que la incertidumbre de la media es menor que la incertidumbre de los retornos, el escalar es cercano a cero, pues se espera que los retornos de equilibrio sean menos volátiles que el histórico de los rendimientos. Por su parte, Lee normalmente establece el valor del escalar entre 0,01 y 0,05 ; por el contrario, Satchell y Scowcroft establecen a menudo el escalar en 1 (Idzorek, 2007).

Una vez especificado el escalar $\tau$ y la matriz de covarianzas de las incertidumbres $\Omega$, todos los términos estarán dados para el cálculo de la fórmula de Black-Litterman derivando en el nueva vector de retornos $E[R]$; las nuevas ponderaciones son calculadas mediante la solución de la ecuación: $w=(\lambda \Sigma)^{-1}$ $\mu$ (Idzorek, 2007).

Desde el punto de vista de Idzorek, el modelo Black-Litterman puede ser visto como una suma de dos portafolios, donde el primero será la ponderación 
original de capitalización del mercado, mientras que el segundo es una serie de posiciones largas y cortas basadas en los views, las cuales pueden subdividirse en pequeños portafolios cada uno asociado a un view específico.

\subsection{Support Vector Regression Machine}

Las Support Vector Machines (SvM) encuentran sus orígenes en las teorías de aprendizaje estadístico introducidas en los años noventa por Vapnik, creadas inicialmente para solucionar problemas de clasificación; sin embargo, los usos de hoy día son mucho más amplios, tales como análisis de series temporales, visión artificial, reconocimiento de caracteres, categorización de texto e hipertexto, todo esto gracias a sus sólidos fundamentos teóricos (Carmona, 2014).

De otra parte, en los términos de Carmona (2014), las SVM pueden ser adaptadas para solucionar problemas de regresión -Support Vector Regression (SVR)-, en consecuencia, funcionan bajo los mismos principios de clasificación, así pues, el objetivo de la tarea de regresión es encontrar los parámetros $w=\left(w_{1}, \ldots, w_{d}\right)$ que permitan definir la función lineal:

$$
f(x)=\left(w_{1} x_{1},+\ldots+w_{d} x_{d}\right)+b=<w, x>+b
$$

Para permitir cierto ruido en los ejemplos de entrenamiento se puede relajar la condición de error entre el valor predicho por la función y el valor real. Para ello, se utiliza la denominada función de pérdida $\varepsilon$-insensile, $L_{\varepsilon}$, caracterizada por ser una función lineal con una zona insensible, de anchura $2_{\varepsilon}$, en la que el error es nulo, y viene definida por Carmona (2014) (figura 9):

$$
L \varepsilon(y, f(x))=\left\{\begin{array}{c}
0 \text { si }|y-f(x)| \leq \varepsilon \\
|y-f(x)|-\varepsilon \text { en otros casos }
\end{array}\right.
$$


Figura 9: Margen Blando SVR

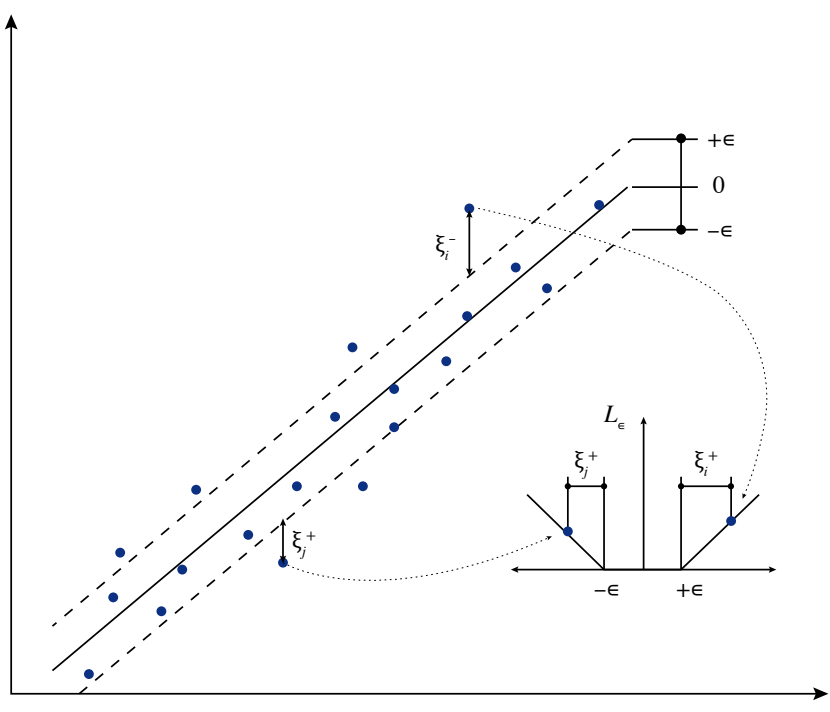

Fuente: Carmona (2014).

Dado que en la práctica es muy difícil que los ejemplos de entrenamiento se ajusten al modelo lineal con un error de predicción igual a cero, se recurre al concepto de margen blando, definiendo dos variables de holgura $\xi_{i}^{+}$y $\xi_{i}^{-}$que permiten cuantificar la magnitud del error. Así, la variable $\xi_{i}^{+}>0$ cuando la predicción del ejemplo $f\left(x_{i}\right)$ es mayor que su valor real, y_i, en una cantidad mayor a $\varepsilon$, es decir, $f\left(x_{i}\right)-y_{i}>\varepsilon$. En otro caso, su valor será 0 . De forma similar, la variable $\xi_{i}^{-}>0$ cuando el valor real del ejemplo es mayor que su predicción en una cantidad superior a $\varepsilon$, es decir, $y_{i}-f\left(x_{i}\right)>\varepsilon$. En otro caso, su valor será 0 (Carmona, 2014).

La suma de todas las variables de holgura permitirá, de alguna manera, medir el coste asociado al número de ejemplos con un error de predicción no nulo; el problema en el caso de regresión queda definido (Carmona, 2014):

$$
\begin{gathered}
\min \frac{1}{2}<w, w>+C \sum_{i=1}^{n}\left(\xi_{i}^{+}+\xi_{i}^{-}\right) \\
\text {S.a. }\left(<w, x_{i}>+b\right)-y_{i}-\varepsilon-\xi_{i}^{+} \leq 0 \\
y_{i}\left(<w, x_{i}>+b\right)-\varepsilon-\xi_{i}^{-} \leq 0 \\
\xi_{i}^{+}, \xi_{i}^{-} \geq 0, i=1, \ldots, n
\end{gathered}
$$


Carmona (2014) señala que los pasos para la transformación del problema dual son: i) obtener la función Lagrangiana; ii) aplicar condiciones Karush-KuhnTucker (KKT); iii) establecer las relaciones entre las variables del problema primal $(w, b, \xi)$ con las del problema dual $(\alpha, \beta)$; iv) establecer restricciones adicionales de las variables duales; v) a partir del resultado del paso iii, eliminar las variables primales de la función Lagrangiana para obtener así el problema dual que se quiere maximizar y la formalización del problema dual:

$$
\begin{gathered}
\max \sum_{i=1}^{n} \alpha_{i}-\frac{1}{2} \sum_{i, j=1}^{n} \alpha_{i} \alpha_{j} y_{i} y_{j}<x_{i}, x_{j}> \\
\text { S.a. } \sum_{i=1}^{n} \alpha_{i} y_{i}=0 \\
0 \leq \alpha_{i} \leq C, i=1, \ldots, n
\end{gathered}
$$

El regresor asociado a la función lineal buscada resulta ser (Carmona, 2014):

$$
f(x)=\sum_{i=1}^{n}\left(a_{i}^{-}-a_{i}^{+}\right)<x, x_{i}>+b^{*}
$$

\section{Aplicación de las Support Vector Regression al Modelo Black-Litterman y su efecto en los FPo colombianos}

Al realizar la comparación de las rentabilidades obtenidas por los diferentes fondos de pensión frente a la rentabilidad mínima reportada en las distintas circulares expedidas por la Superintendencia Financiera de Colombia para el periodo comprendido entre agosto de 2012 y julio de 2019 se tiene (figuras 10 , 11 y 12$)$ : 
Figura 10: Fondo Conservador 2012-2019

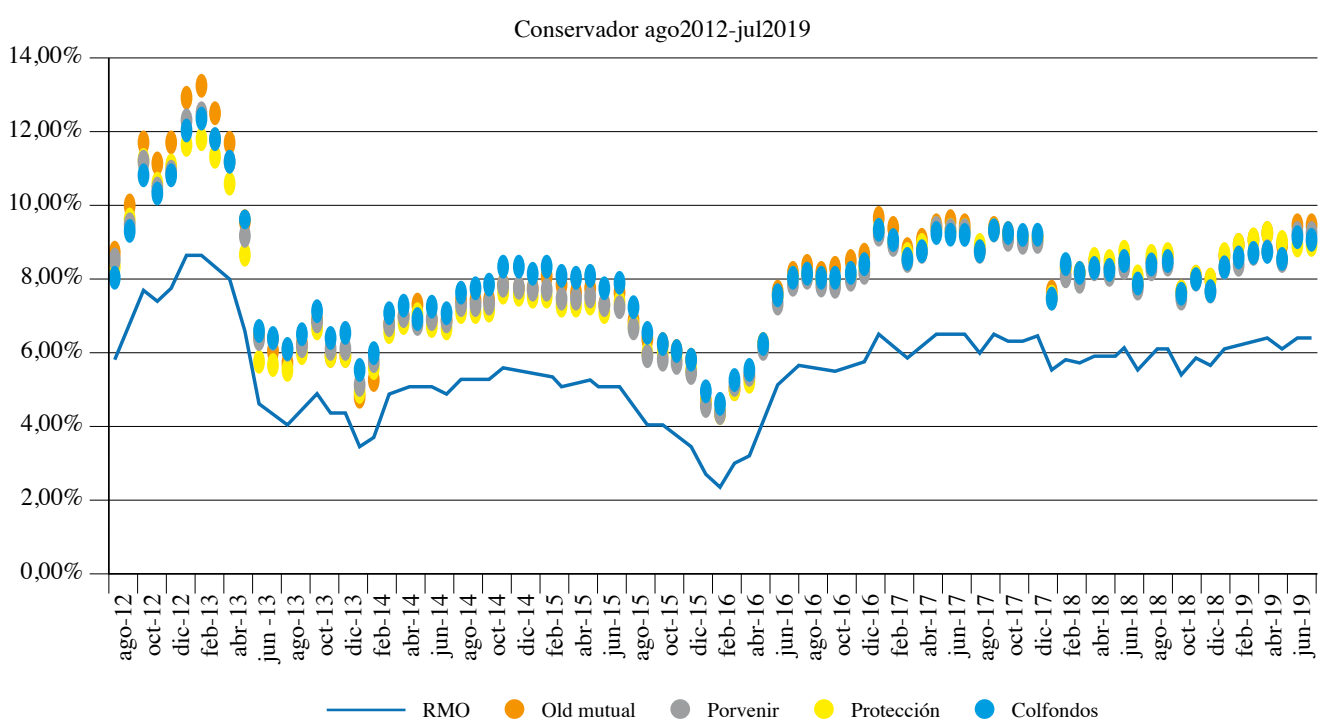

Fuente: SFC, elaboración propia.

Figura 11: Fondo Moderado 2013-2019

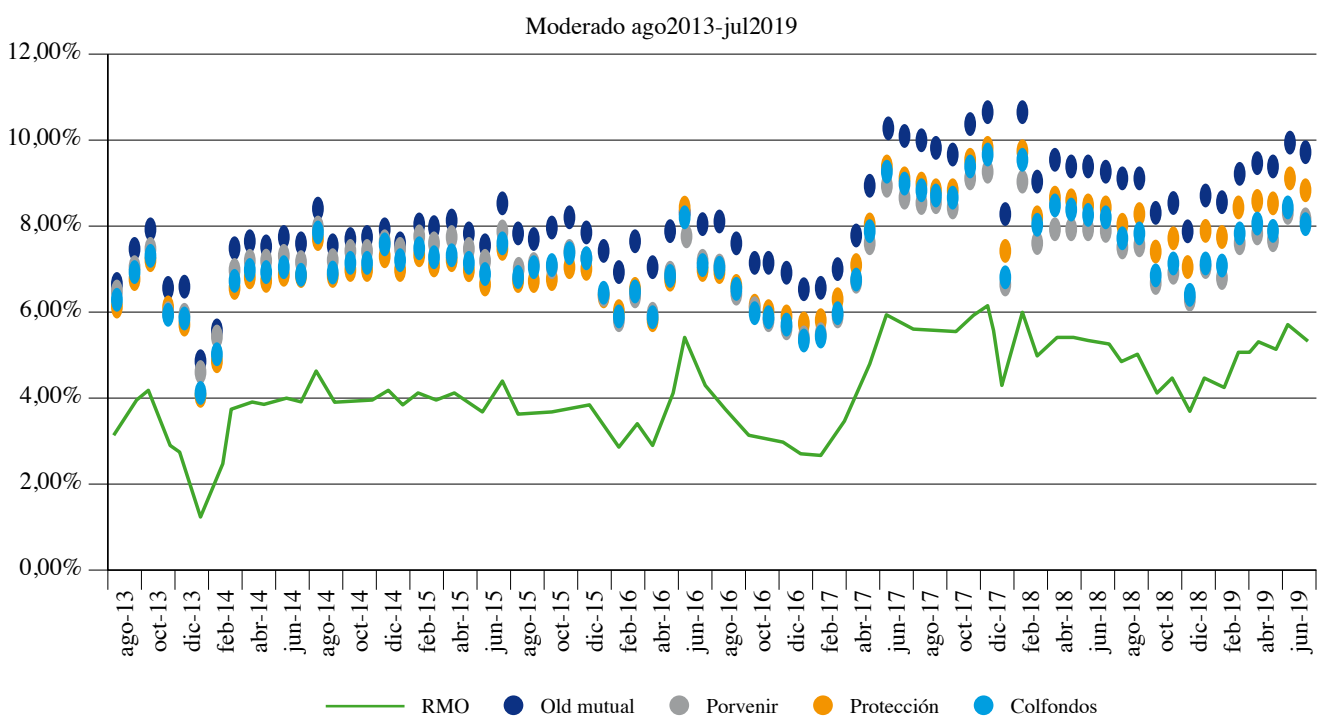

Fuente: SFC, elaboración propia. 
Figura 12: Fondo Mayor Riesgo 2013-2019

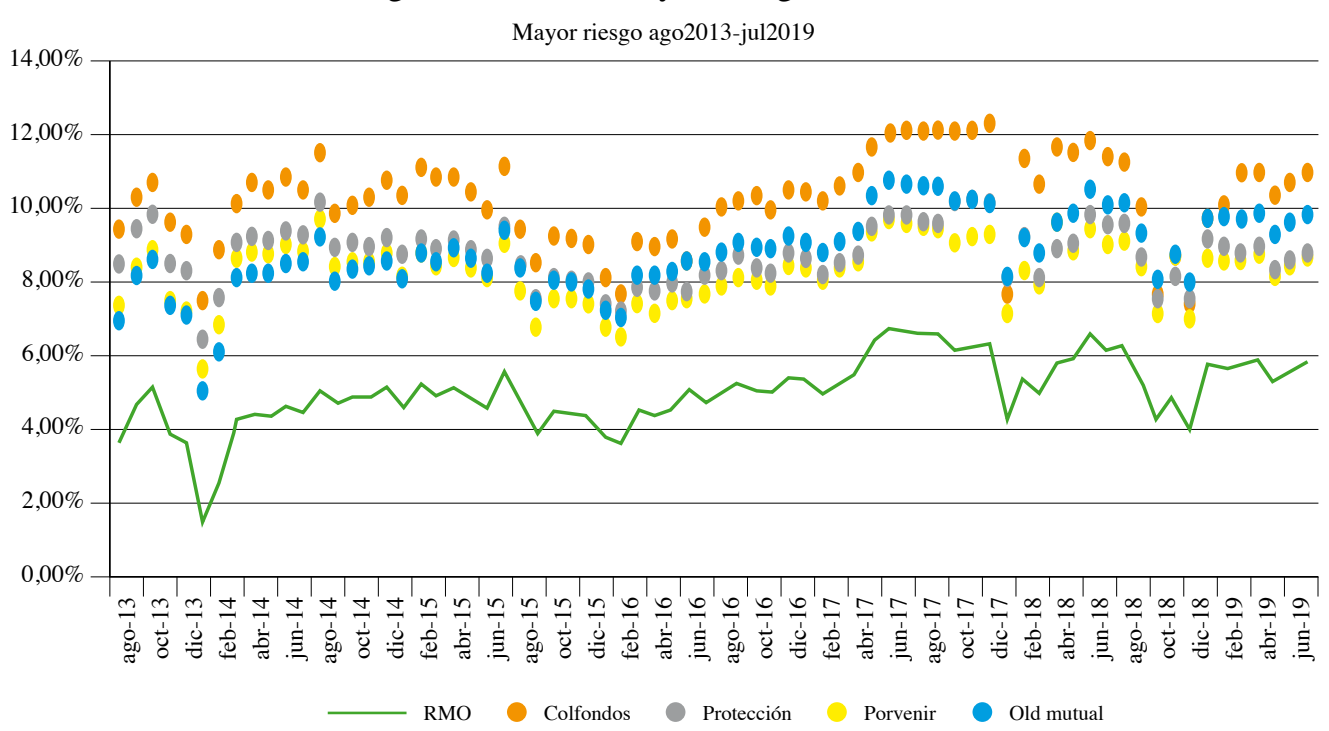

Fuente: SFC, elaboración propia.

Se observa que las AFP tienen un rendimiento muy similar en cada tipo de fondo; adicionalmente, equidistan de la rentabilidad mínima obligatoria, de una manera más notoria que el portafolio conservador frente al riesgoso y moderado; quien refleja un comportamiento más disímil es el portafolio de mayor riesgo, donde se evidencia mayor dispersión de rentabilidades entre las cuatro administradoras. La administradora que tiene un comportamiento histórico más alejado de la RMO y de sus pares es Colfondos.

Este comportamiento bien puede obedecer a la existencia de colusión de las administradoras como respuesta a la exigibilidad de la rentabilidad mínima, ya que esta medida regulatoria de tipo coercitivo exige la compensación con patrimonio neto frente a los descalces en términos de rentabilidad mínima, razón más que suficiente para que las administradoras se restrinjan a la hora de estructurar cada uno de sus fondos.

Siguiendo a Roy (1952), al crear un indicador que mida el grado de colusión descrito como: $\frac{E\left[r_{p}\right]-R M O}{\sigma_{p}}$, donde $E\left[r_{p}\right]$ es el valor esperado de los rendimientos del portafolio de cada AFP para los periodos de agosto de 2012 a julio de 2019, 
y $R M O$ la rentabilidad mínima esperada obligatoria calculada por la SFC para los periodos de agosto de 2012 a julio de 2019; finalmente, $\sigma_{p}$ es la desviación estándar de los rendimientos del portafolio para cada AFP; los datos se muestran en la tabla 3.

Tabla 3: Índice de colusión

\begin{tabular}{|l|c|c|c|}
\hline \multicolumn{4}{|c|}{ Resultados indicador agosto 2012-julio 2019 } \\
\hline Fondo & Moderado & Conservador & Mayor riesgo \\
\hline Horizonte & 2,3775 & 1,3332 & 7,4202 \\
\hline Old Mutual & 1,7640 & 1,4024 & 4,1776 \\
\hline Porvenir & 1,9005 & 1,4408 & 4,9776 \\
\hline Proteccion & 1,6773 & 1,4178 & 3,8419 \\
\hline Colfondos & 1,7040 & 1,6594 & 3,4680 \\
\hline
\end{tabular}

Fuente: elaboración propia.

Como se observa, para los portafolios moderado y conservador el indicador es muy similar entre las administradoras Old Mutual, Porvenir y Protección, pero muy diferente en el caso de portafolio de mayor riesgo, por consiguiente, este indicador nos lleva a pensar que las ponderaciones de los activos que componen estos portafolios de las AFP son muy similares, lo que muestra la existencia de un grado de colusión; sin embargo, no se trata de una colusión per se, sino que corresponde a una respuesta natural dada la exigibilidad de una RMO y el limitado margen de acción en cuanto a los límites de las inversiones admisibles. En consecuencia, la rentabilidad del esquema multifondos está en función del RMO y las inversiones admisibles, y dado que los ingresos de las AFP no están relacionadas con las rentabilidades de sus fondos, es decir, no existe beneficio directo por la constitución de portafolios eficientes, sino que su comisión es determinada por la cantidad de aportantes (afiliados), es posible intuir que no existe un incentivo para generar grandes excesos de índice de Sharpe que los aleje de la RMO; sin embargo, esta posición asumida por las AFP puede ser contraproducente en la medida que los cotizantes, como verdaderos tomadores de riesgo y según su etapa de vida laboral, migren hacia el Régimen de Prima Media; claro está que depende de la conciencia del aportante respecto de la relación de la rentabilidad ajustada por riesgo de su fondo. 
Ahondando un poco más en términos de la estructuración de los portafolios de las AFP, la cual deriva en los rendimientos históricos antes señalados y comparados con la rentabilidad mínima, en el periodo puntual de julio de 2019 se encuentran ponderaciones muy similares para cada tipo de fondo, como se detalla en la figura 13.

Figura 13: Composición portafolio moderado

Portafolio Moderado Protección S.A julio 2019

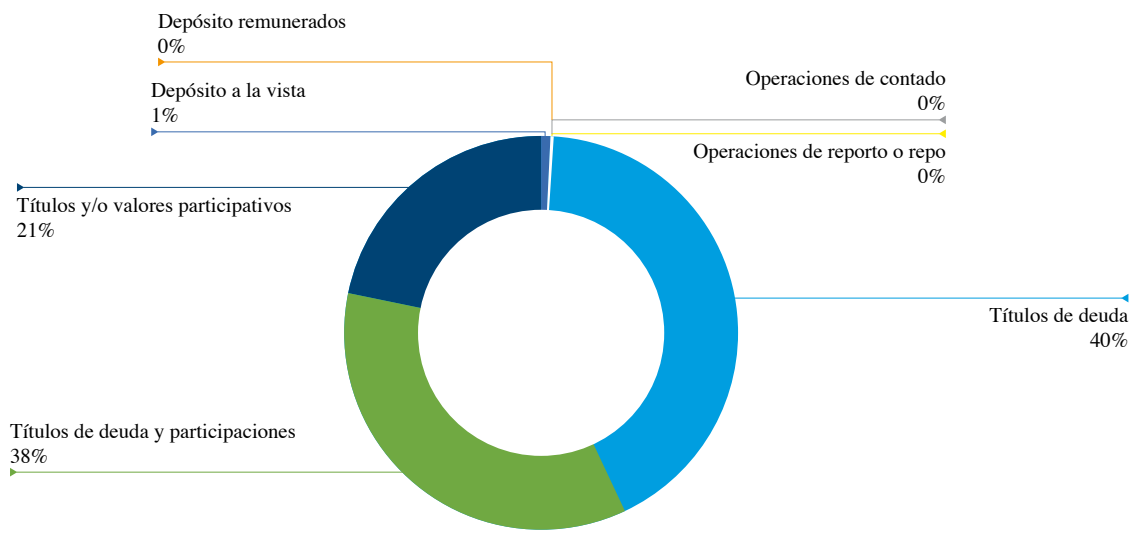

Portafolio Moderado Porvenir S.A julio 2019

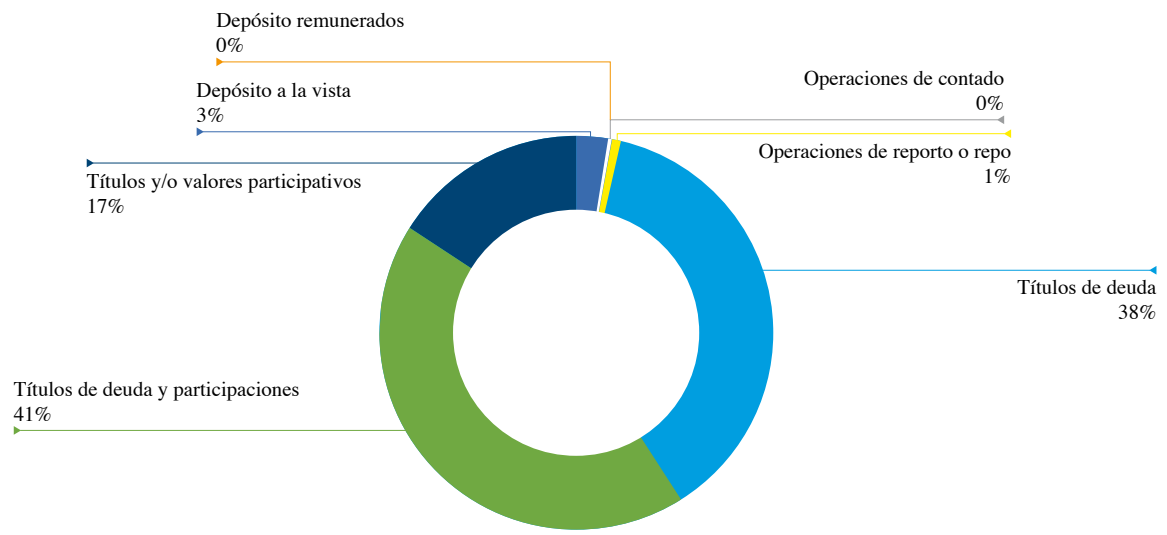


Portafolio Moderado Old mutual S.A julio 2019

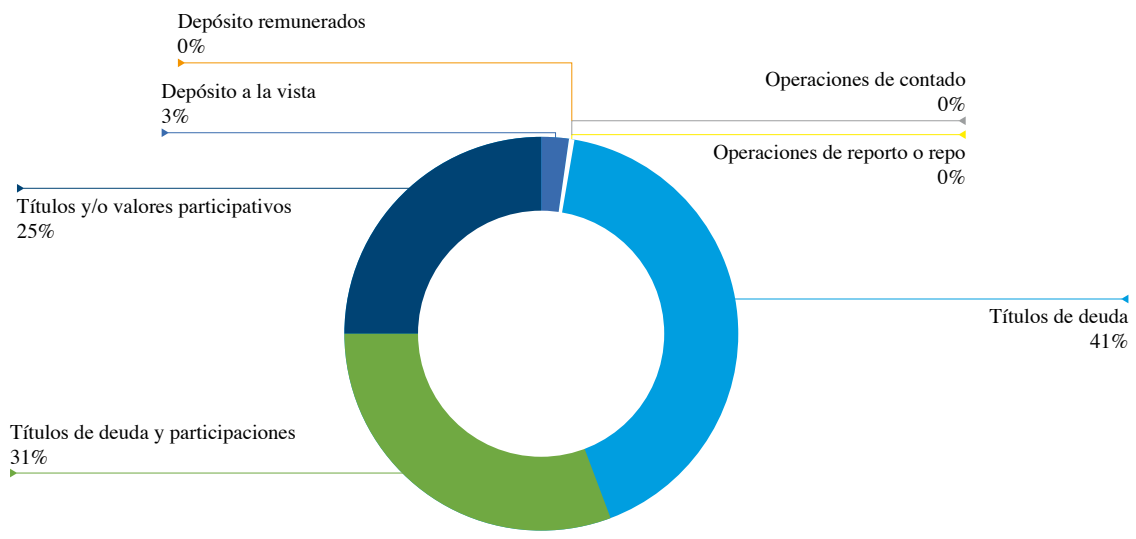

Portafolio Moderado Old mutual S.A julio 2019

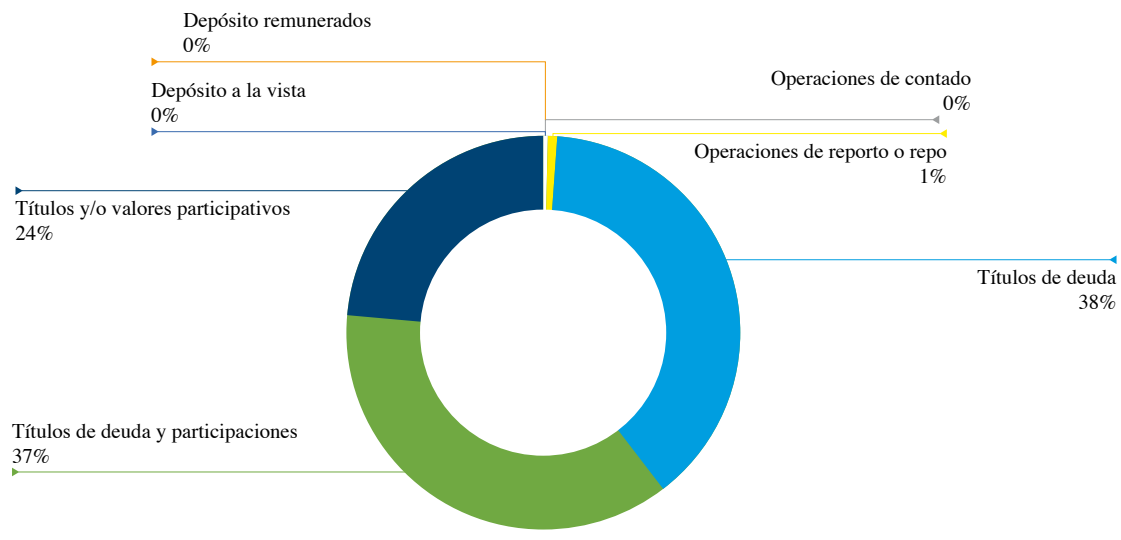

Fuente: SFC, elaboración propia.

Las ponderaciones de las diferentes AFP en este tipo de portafolios están orientadas a los cotizantes con edades alrededor de los 50 años, quienes pueden asumir volatilidades moderadas que, como se observa, provienen principalmente de la proporción asignada a la renta variable y títulos de deuda extranjeros; la posición principal en esta clase de inversión es en mutual founds, mientras que la participación en renta fija en mayor proporción se encuentra en títulos de deuda pública (TES) colombianos. 


\section{Figura 14: Composición portafolio conservador}

Portafolio Conservador Protección S.A julio 2019

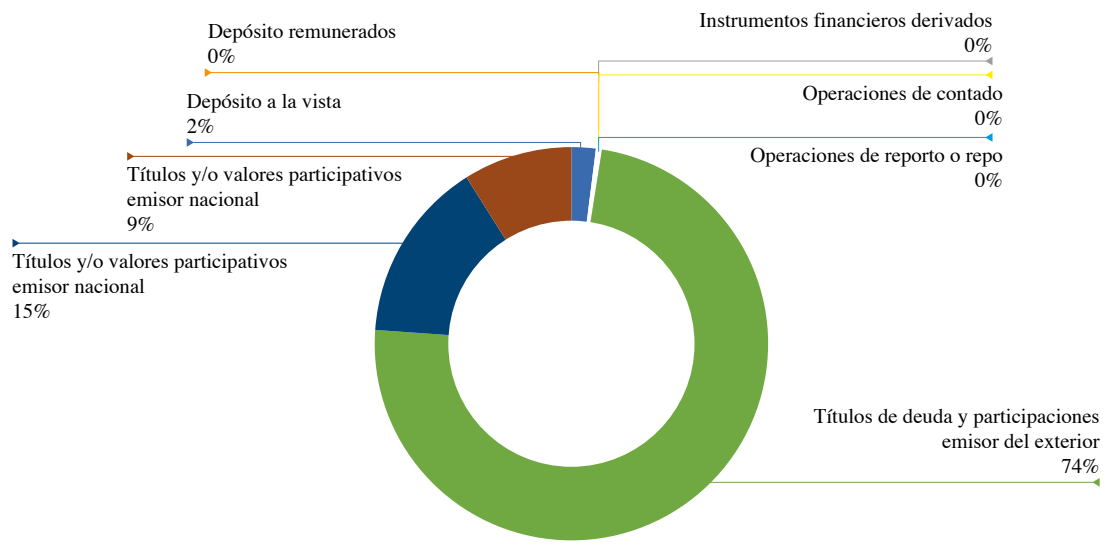

Portafolio Conservador Porvenir S.A julio 2019

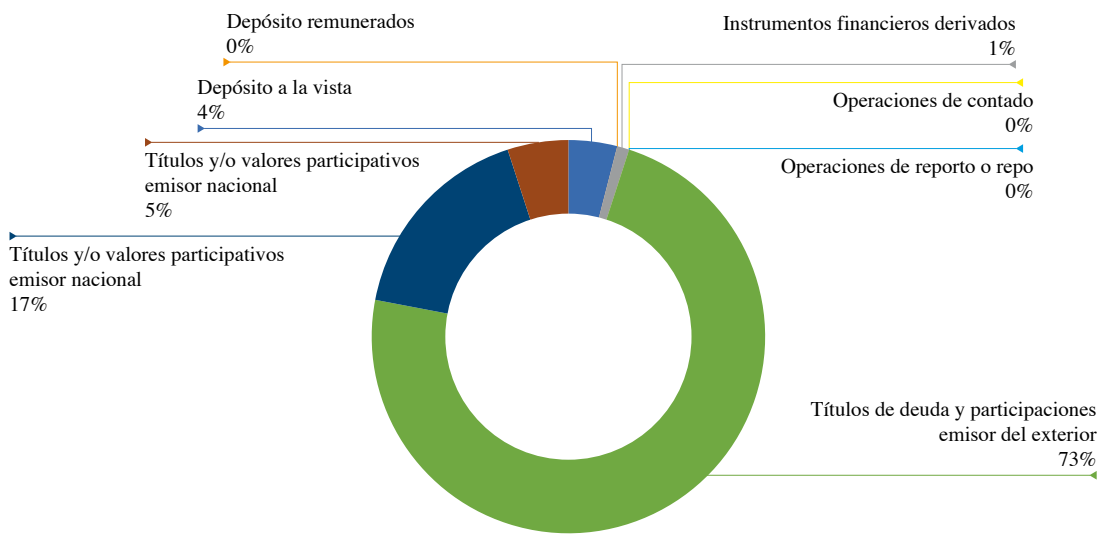

Portafolio Conservador Old mutual S.A julio 2019

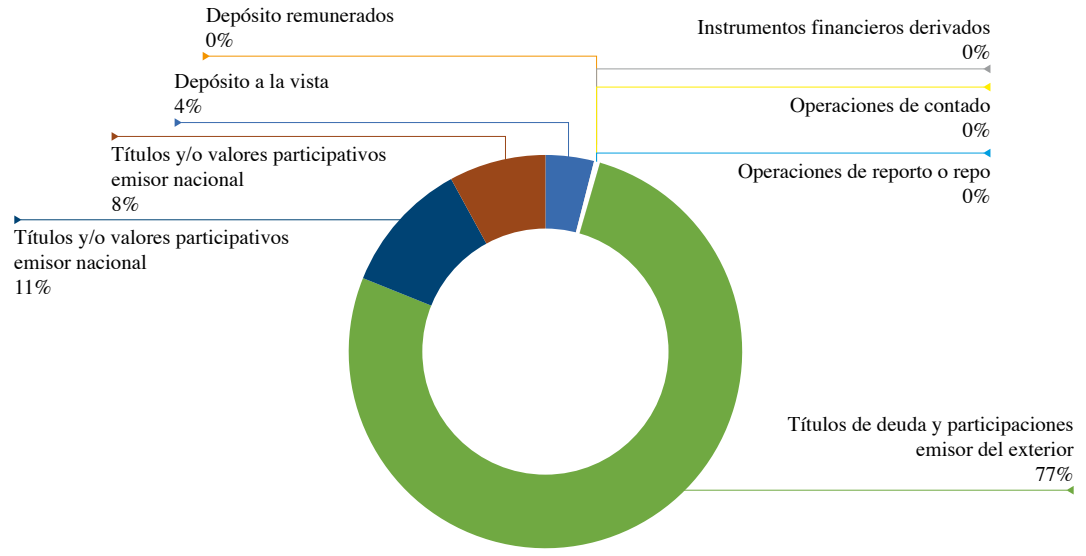


Portafolio Mayor Riesgo Old mutual S.A julio 2019

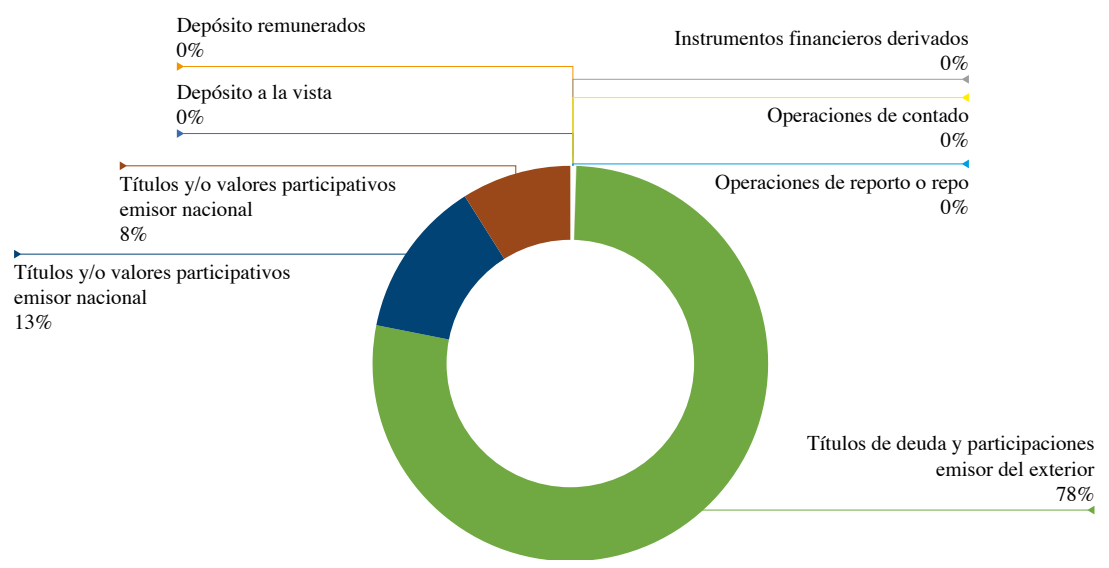

Fuente: SFC, elaboración propia.

Como era de esperarse para este tipo de portafolios, y para la clase de cotizantes que lo componen, es decir, personas cercanas a la edad de retiro quienes esperan baja exposición al riesgo y mantenimiento de su riqueza como garantía de consumo intertemporal, en comparación con el portafolio conservador, la participación en deuda pública colombiana es mayor (figura 14).

Figura 15: Composición portafolio mayor riesgo

Portafolio Mayor Riesgo Protección S.A julio 2019

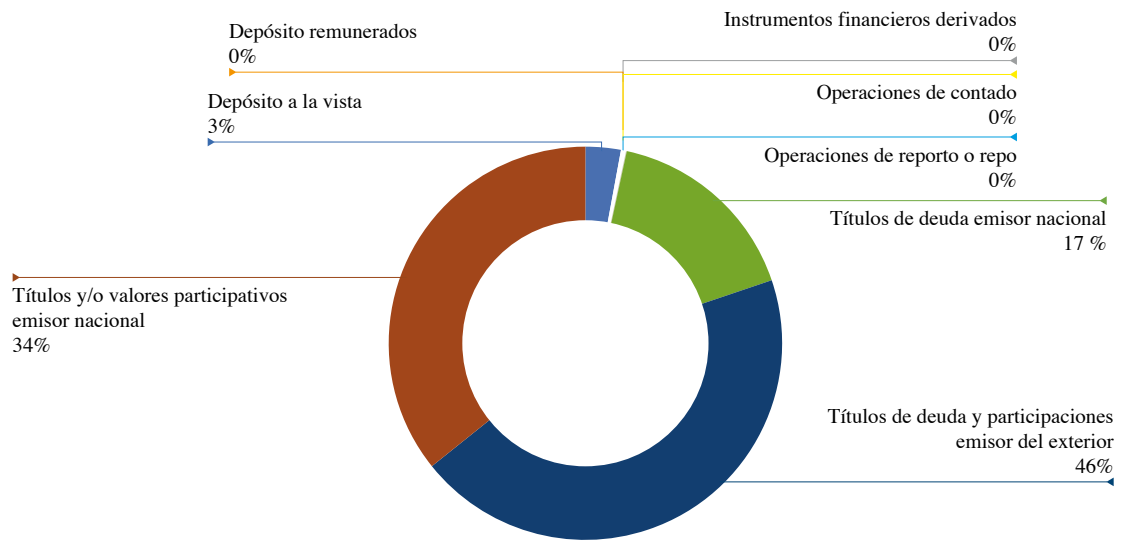


Portafolio Mayor Riesgo Old mutual S.A julio 2019

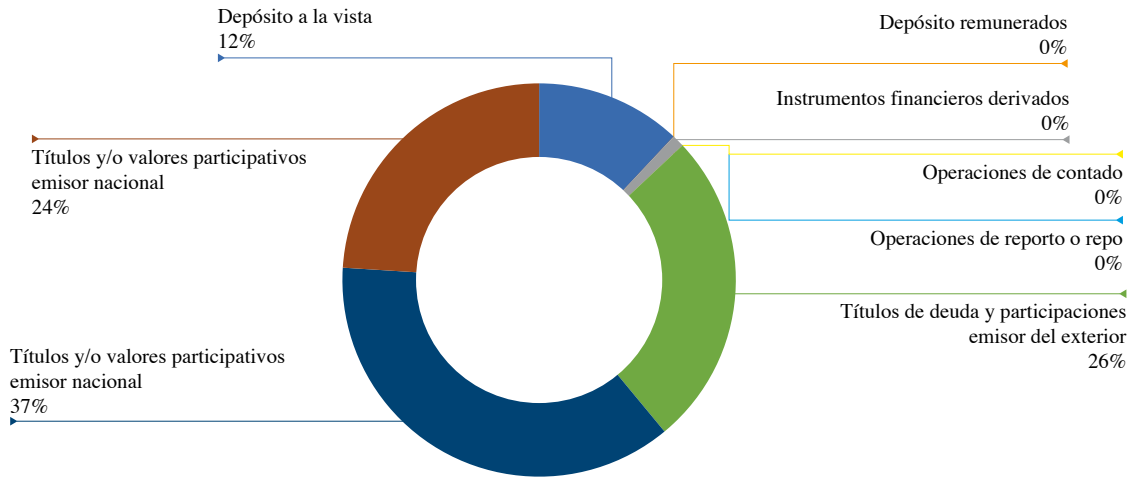

Portafolio Mayor Riesgo Old mutual S.A julio 2019

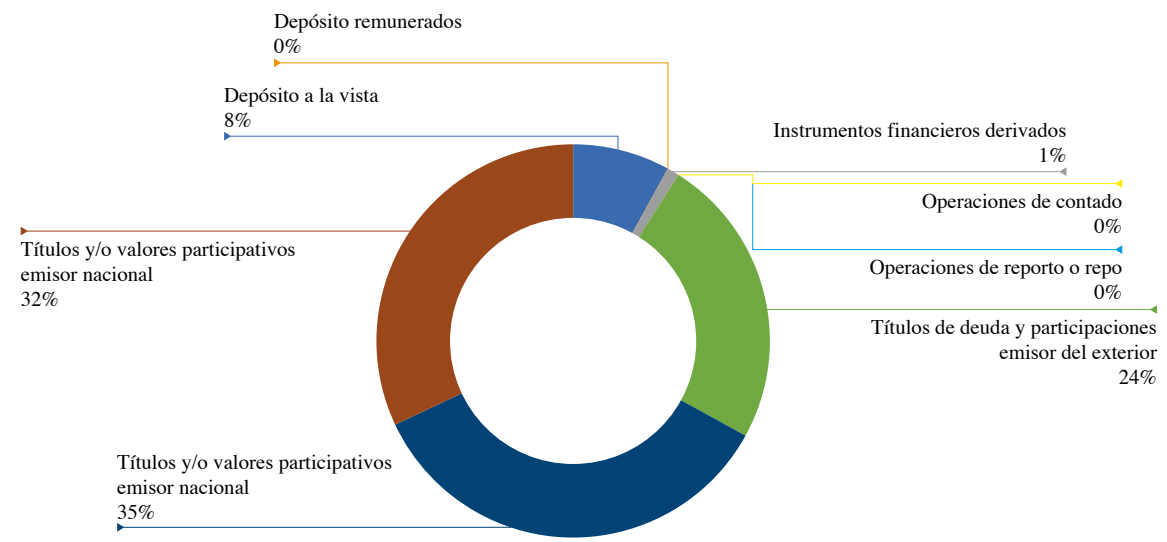

Portafolio Mayor Riesgo Colfondos S.A julio 2019

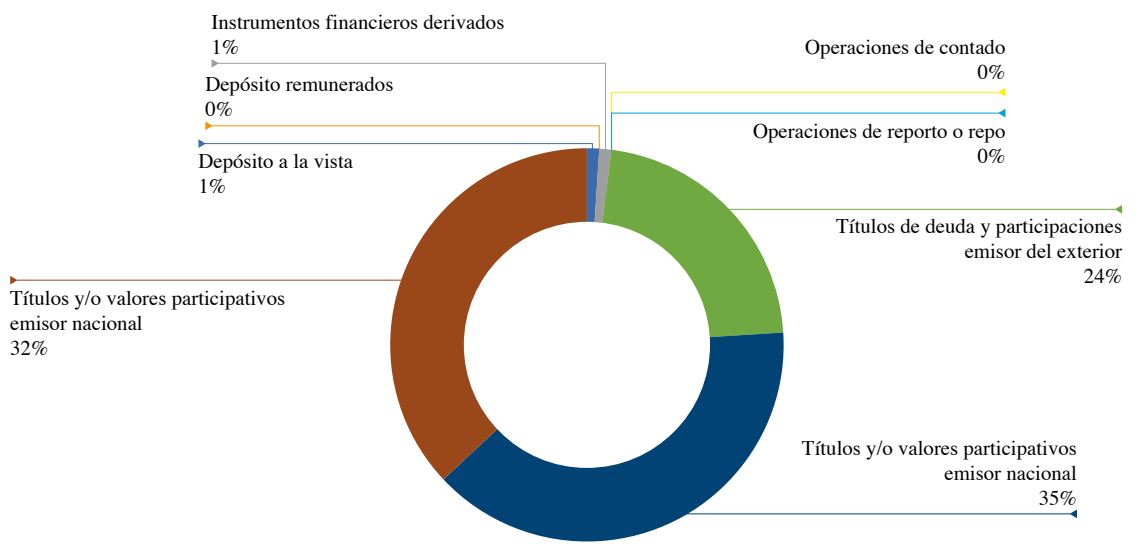

Fuente: SFC, elaboración propia. 
Para el caso del fondo de mayor riesgo (figura 15), se observa una mayor diferencia entre las posiciones de las distintas AFP, contrario a lo evidenciado en el moderado y conservador; los cotizantes que componen este portafolio son personas jóvenes que inician su etapa laboral, usualmente tomadores de riesgo dado el horizonte de tiempo para el goce efectivo del fondo de retiro; la ponderación de este portafolio está dirigida en mayor medida a participación en títulos tanto de emisor nacional como extranjero, el común denominador de las diferentes AFP respecto a la posición extranjera está orientado hacia mutual founds que siguen índices accionarios.

Como se ha podido evidenciar, las posiciones de las AFP en los diferentes fondos no difieren de forma significativa, sin embargo, es necesario evaluarlas desde una perspectiva de desempeño que permita vislumbrar la gestión a partir de la dinámica riesgo-varianza; para este fin, se analizará desde el índice de Sharpe. Dado que el índice requiere un activo libre de riesgo, se tomará para todos los fondos los TES julio 2024, los rendimientos históricos desde agosto 2013 hasta julio 2019 y la desviación de los mismos; con el ánimo de comparar el desempeño contra la exigibilidad normativa, y en el entendido de que el rendimiento mínimo obligatorio proviene de rentabilidades históricas de los mismos fondos y ponderación de un portafolio de referencia calculado por la SFC, se tomarán los rendimientos históricos obligatorios (RMO), su desviación y el mismo activo libre de riesgo para asemejarlo a un portafolio benchmark (tabla 4).

Tabla 4: Resultados índice Sharpe, agosto 2012-julio 2019

\begin{tabular}{|c|c|c|c|c|c|c|}
\hline Fondo & Moderado & $\begin{array}{c}\text { Moderado } \\
\text { RMO }\end{array}$ & Conservador & $\begin{array}{c}\text { Conservador } \\
\text { RMO }\end{array}$ & Mayor riesgo & $\begin{array}{c}\text { Mayor } \\
\text { riesgo Rmo }\end{array}$ \\
\hline Horizonte & 9,0521 & \multirow{5}{*}{3,8221} & 3,2415 & \multirow{5}{*}{4,0984} & 11,6684 & \multirow{5}{*}{3,2050} \\
\hline Old Mutual & 6,7394 & & 4,2002 & & 6,2575 & \\
\hline Porvenir & 6,1034 & & 4,5502 & & 7,4210 & \\
\hline Proteccion & 6,4566 & & 4,5450 & & 9,1127 & \\
\hline Colfondos & 7,2950 & & 4,9954 & & 6,6155 & \\
\hline
\end{tabular}

Fuente: elaboración propia.

El índice Sharpe permite ver la prima por unidad de riesgo de cada fondo; en este sentido, la gestión adelantada por las AFP en los portafolios de moderado y mayor riesgo resulta incluso mejor que la identificada por el portafolio de 
referencia calculado por la SFC; para el conservador, las administradoras cuentan con ratios similares, relación que también se observó en el índice de colusión; en consecuencia, se encuentra una estricta relación frente a la composición en este portafolio por parte de las administradoras, como se evidenció anteriormente en el análisis del fondo para el periodo de julio de 2019 (tabla 5).

Tabla 5: Índice colusión frente a Índice Sharpe

\begin{tabular}{|l|c|c|c|c|c|c|}
\hline \multicolumn{1}{|c|}{ Fondo } & $\begin{array}{c}\text { Índice } \\
\text { colusión } \\
\text { portafolio } \\
\text { moderado }\end{array}$ & $\begin{array}{c}\text { Índice Sharpe } \\
\text { portafolio } \\
\text { moderado }\end{array}$ & $\begin{array}{c}\text { Índice } \\
\text { colusión } \\
\text { portafolio } \\
\text { conservador }\end{array}$ & $\begin{array}{c}\text { Índice Sharpe } \\
\text { portafolio } \\
\text { conservador }\end{array}$ & $\begin{array}{c}\text { Índice } \\
\text { colusión } \\
\text { portafolio } \\
\text { mayor riesgo }\end{array}$ & $\begin{array}{c}\text { Índice Sharpe } \\
\text { portafolio } \\
\text { mayor riesgo }\end{array}$ \\
\hline Old Mutual & 2,3775 & 6,7394 & 1,4024 & 4,2002 & 3,4680 & 6,2575 \\
\hline Porvenir & 1,6773 & 6,1034 & 1,4408 & 4,5502 & 3,8419 & 7,4210 \\
\hline Proteccion & 1,7040 & 6,4566 & 1,4178 & 4,5450 & 4,9776 & 9,1127 \\
\hline Colfondos & 1,9005 & 7,2950 & 1,6594 & 4,9954 & 4,1776 & 6,6155 \\
\hline
\end{tabular}

Fuente: elaboración propia.

Dada la semejanza entre el índice de colusión y el ratio Sharpe, principalmente en el fondo conservador, puede concluirse que es evidente la existencia de un efecto manada por parte de las AFP en el sentido de estructuración de portafolios similares; de igual manera, el índice de Sharpe muestra que los cotizantes están asumiendo mayores unidades de riesgo por los rendimientos obtenidos en los diferentes fondos; en consecuencia, la gestión de portafolios por parte de las AFP es ineficiente y, a su vez, es asumida por el fondo de retiro del cotizante, lo que se traduce en generación de riqueza subóptima para el consumo intertemporal del cotizante una vez se retire de la fuerza laboral.

\subsection{Support Vector Regression como alternativa de mejora del modelo Black-Litterman}

A fin de crear un portafolio teórico aplicable a los fondos de pensiones colombianos se emplearán las series diarias para los periodos comprendidos entre agosto de 2012 y julio de 2019 de los siguientes índices de renta variable y renta fija (tabla 6): 
Tabla 6: Activos portafolio aplicable

\begin{tabular}{|l|l|l|}
\hline \multicolumn{1}{|c|}{ Clase de activo } & \multicolumn{1}{|c|}{ Descripción } & Fuente \\
\hline \multirow{2}{*}{$\begin{array}{l}\text { Renta variable de } \\
\text { Colombia }\end{array}$} & $\begin{array}{l}\text { COLCAP Renta variable del mercado colombiano negociada en la } \\
\text { Bolsa de Valores de Colombia }\end{array}$ & \multirow{2}{*}{ BVC } \\
\cline { 2 - 4 } & COLEQTY indice 40 acciones con mejor función de selección de la BVC & \\
\hline $\begin{array}{l}\text { Renta fija de } \\
\text { Colombia }\end{array}$ & COLTES índice que provee una serie de referencia del mercado público & BVC \\
\cline { 2 - 4 } & DTF RATE Index Tasa de captación de los bancos CDT 90 días & Bloomberg \\
\hline $\begin{array}{l}\text { Deuda mercados } \\
\text { emergentes }\end{array}$ & JPEIPLUS Index Indice de Bonos de Mercados emergentes & Bloomberg \\
\hline $\begin{array}{l}\text { Deuda soberana de } \\
\text { Estados Unidos }\end{array}$ & SBUS57L Index índice bonos del tesoro americano & Bloomberg \\
\hline $\begin{array}{l}\text { Renta variable de } \\
\text { Estados Unidos }\end{array}$ & $\begin{array}{l}\text { SPX Index Las 500 compañías principales en industrias líderes de } \\
\text { la economía de los Estados Unidos, principalmente de alta capita- } \\
\text { lización. }\end{array}$ & Bloomberg \\
\hline $\begin{array}{l}\text { Renta variable de } \\
\text { mercados mesa- } \\
\text { rrollados }\end{array}$ & $\begin{array}{l}\text { MXEA Index captura una representación de gran y mediana capita- } \\
\text { lización de 21 países con mercados desarrollados }\end{array}$ & Bloomberg \\
\hline $\begin{array}{l}\text { Renta variable de } \\
\text { mercados emer- } \\
\text { gentes }\end{array}$ & MSEUEGFL Index & Bloomberg \\
\hline Renta variable & EUR_ USD & Bloomberg \\
\hline
\end{tabular}

Fuente: Bloomberg (2019).

Ahora bien, como se vio en Trujillo Segura (2009), una de las principales ventajas del modelo Black-Litterman es la posibilidad de participación de los administradores de portafolio mediante perspectivas del mercado que terminan influenciando en las ponderaciones de los mismos; en este sentido, si se cuenta con una alternativa en la estructuración de los views con menor grado de incertidumbre sobre las expectativas de los activos en el portafolio, esto derivaría en portafolios mejor diversificados, mayor confianza para el administrador en la gestión del portafolio enfocándose en resultados óptimos que se apartarían de la rentabilidad mínima obligatoria, llevando así a la mejora competitiva entre las AFP que, en suma, generaría mejores resultados en los fondos de retiro de sus afiliados.

En este sentido, los Support Vector Regression pueden ser una alternativa para los administradores de fondos en cuanto a la estructuración de los views, en tanto 
que dentro de sus bondades se encuentra que no son una técnica paramétrica, contrario a los modelos generalizados de regresión lineal; además, permiten la construcción de un modelo no lineal sin cambiar las variables explicativas, lo que ayuda a una mejor interpretación del modelo resultante (Carmona, 2014); la aplicación de SVR a la serie histórica de las inversiones admisibles de los fondos de pensión permite obtener resultados como los que se muestran en la figura 16 y la tabla 7 :

Figura 16: Resultado aplicación SVR

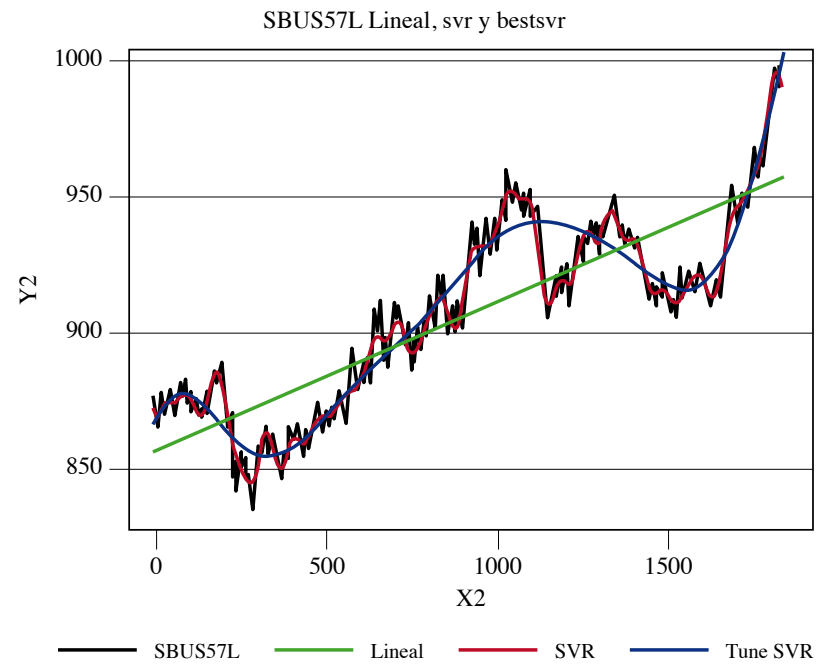

Fuente: elaboración propia.

Tabla 7: Error cuadrático medio serie SBUS57L

\begin{tabular}{|c|c|c|c|}
\hline & RMSE Lineal & RMSE svr & RSM Bestsvr \\
\hline SBUS57L & 18,38 & 3,69 & 9,21 \\
\hline
\end{tabular}

Fuente: elaboración propia.

Se observa gráficamente un mejor ajuste del modelo SVR respecto del lineal y del predicho (Best Model) mediante el uso de la función tune de Rstudio, que además genera un alto costo computacional en el sentido de tiempo de ejecución y compromiso de recurso computacional para la solución óptima de cada variable, razón por la cual, la mejor opción para determinar el modelo fue mediante la calibración de la función svm de Rstudio, que logró buenos resultados en términos de ajuste y error cuadrático, como se señala en la figura 17 y la tabla 8 . 
Figura 17: Modelos SVR
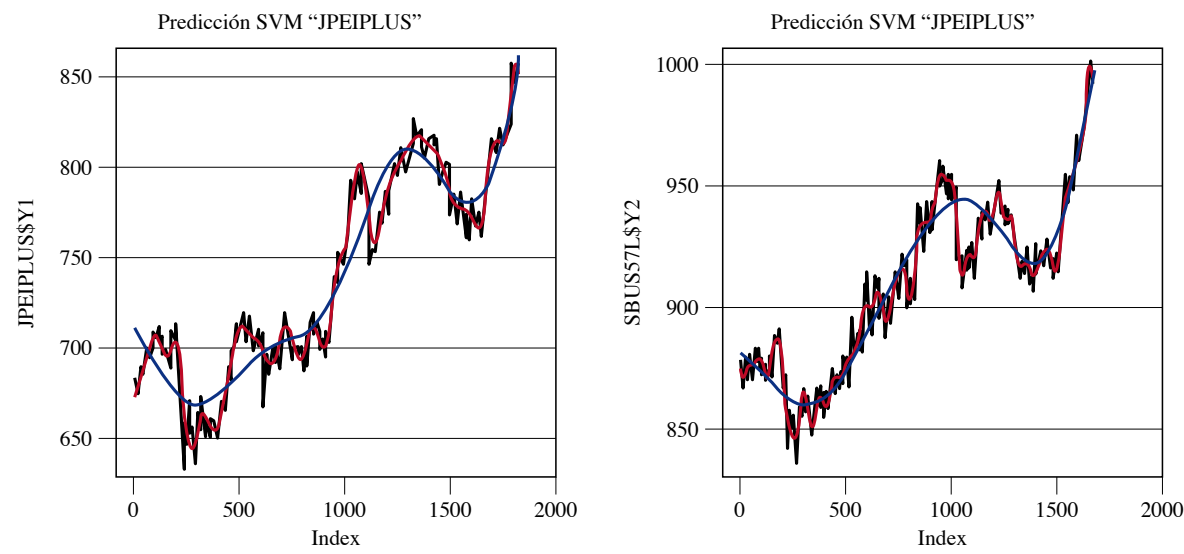

— Data - SVM Predicción - tuned SVM Predicción Predicción SVM "SPX”
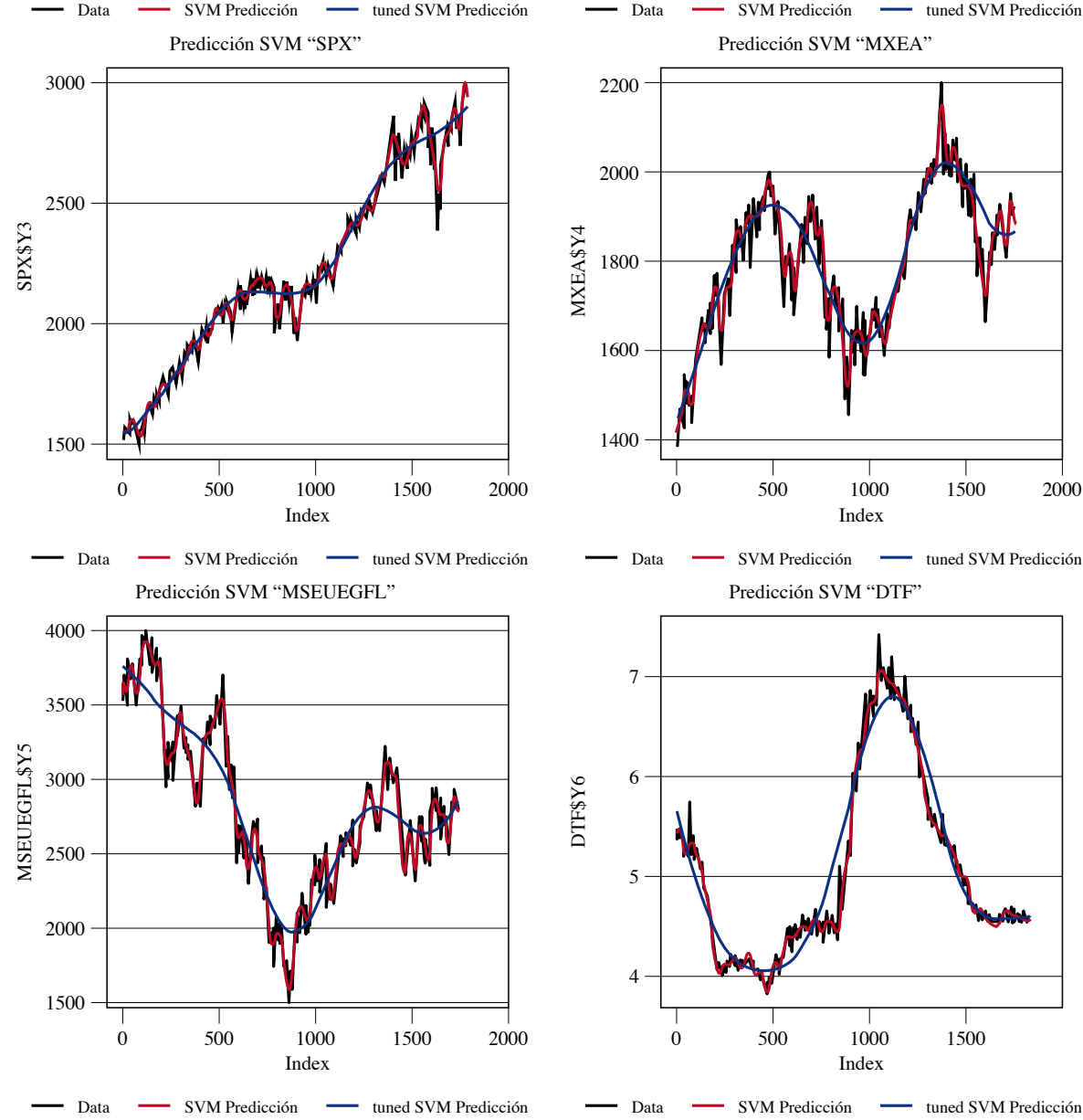

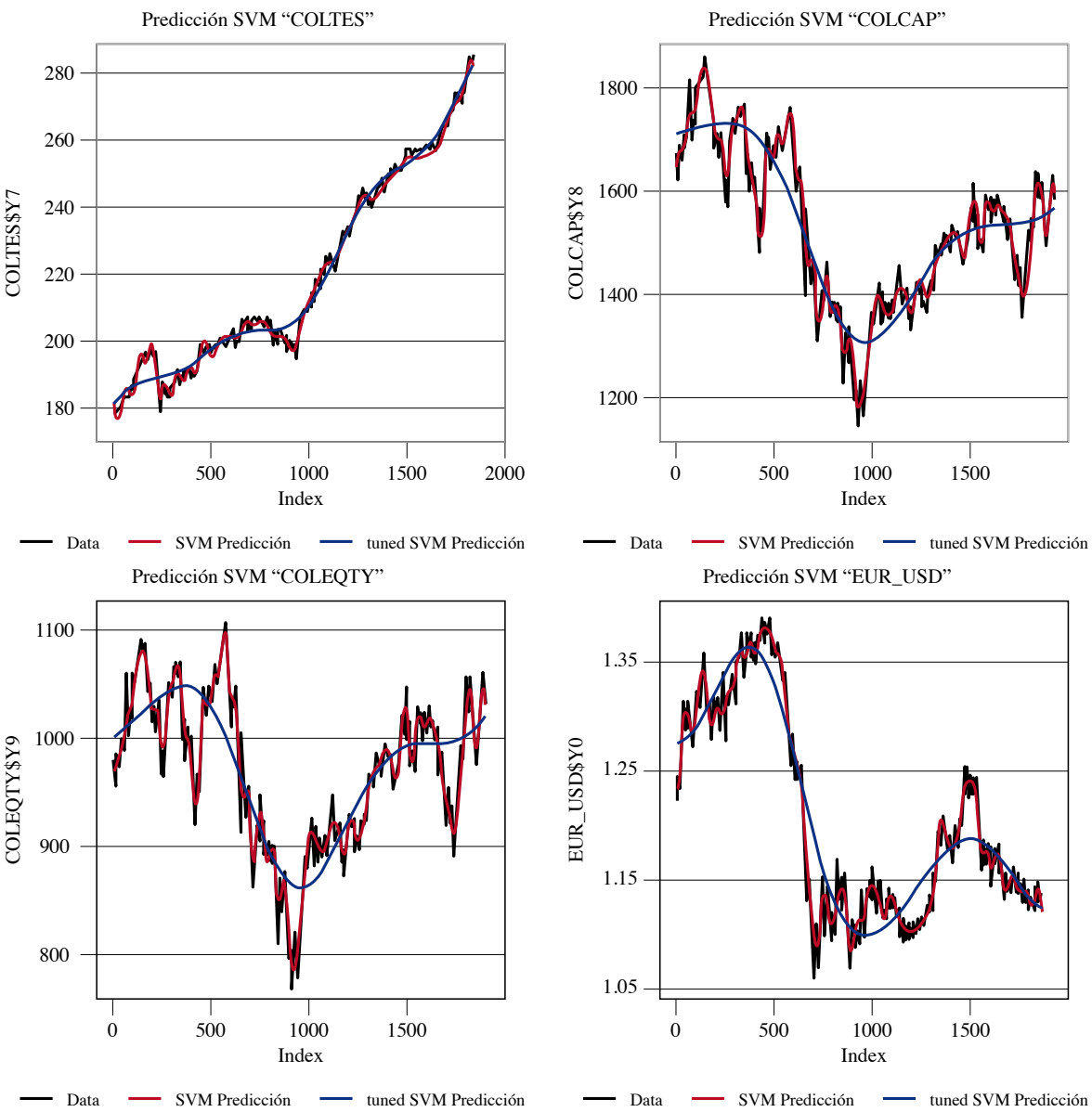

Fuente: elaboración propia.

Tabla 8: Errores de selección del modelo SVR

\begin{tabular}{|c|c|c|}
\hline Serie & RMSE SVR ajustado & RMSE SVR inicial \\
\hline JPEIPLUS & 6,59 & 17,57 \\
\hline SBUS57L & 3,69 & 9,95 \\
\hline SPX & 30,34 & 65,10 \\
\hline MXEA & 23,01 & 58,87 \\
\hline MSEUEGFL & 55,25 & 192,82 \\
\hline DTF & 0,09 & 0,25 \\
\hline
\end{tabular}




\begin{tabular}{|c|c|c|}
\hline Serie & RMSE SVR ajustado & RMSE SVR inicial \\
\hline COLTES & 1,68 & 3,18 \\
\hline COLCAP & 20,83 & 74,03 \\
\hline COLEQTY & 13,15 & 47,85 \\
\hline EUR _ USD & 0,01 & 0,03 \\
\hline
\end{tabular}

Fuente: elaboración propia.

Una vez seleccionados los modelos con menores errores y mejores ajustes de los a priori, se procedió a predecirlos un paso delante $\mathrm{y}$, de esta manera, se construyeron el vector Q y la matriz P del modelo Black-Litterman, que se emplean para calcular la distribución posteriori (Omega). A continuación, se muestra una gráfica del ajuste del modelo y datos predichos (figura 18).

Figura 18: Predicción SVR

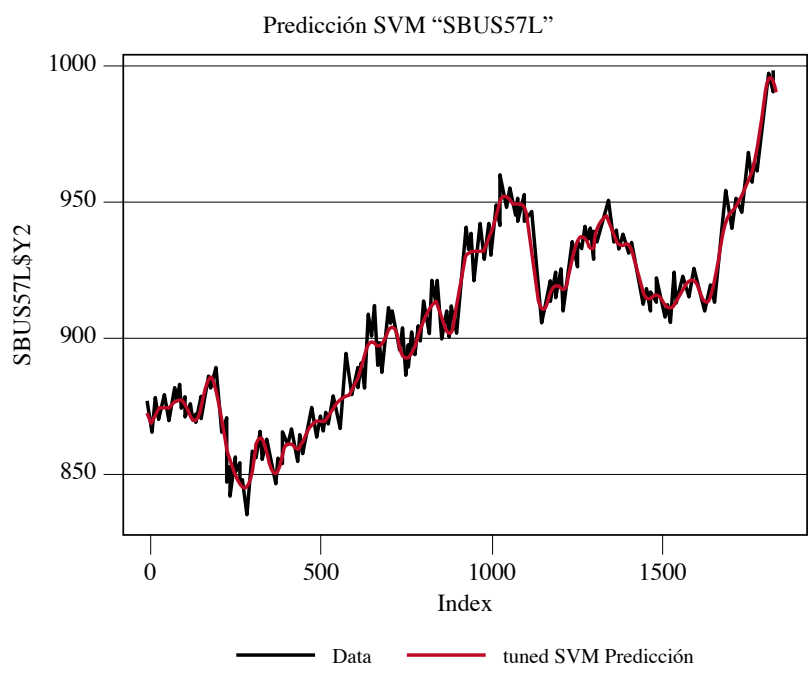

Fuente: elaboración propia.

En este sentido, y teniendo en cuenta que el modelo Black-Litterman permite views absolutos, estos se determinaron a partir del cálculo de los rendimientos log normales respecto del último dato conocido y la predicción para cada una de las variables; y siguiendo a Idzorek (2007), se obtienen los posteriori de los valores esperados Black-Litterman que, comparados, arrojan (tabla 9): 
Tabla 9: Posteriori BL y BL con SVR

\begin{tabular}{|c|c|c|}
\hline Serie & Posteriori BLM con omega SVR & Posteriori BLM \\
\hline JPEIPLUS & $-0,008$ & 0,000 \\
\hline SBUS57L & 0,004 & $-0,001$ \\
\hline SPX & 0,008 & 0,001 \\
\hline MXEA & 0,001 & 0,001 \\
\hline MSEUEGFL & 0,003 & $-0,001$ \\
\hline DTF & $-0,010$ & $-0,001$ \\
\hline COLTES & $-0,005$ & 0,001 \\
\hline COLCAP & $-0,008$ & 0,001 \\
\hline COLEQTY & $-0,007$ & 0,001 \\
\hline EUR - USD & 0,000 & $-0,001$ \\
\hline
\end{tabular}

Fuente: elaboración propia.

Se observa gran cantidad de diferencias entre los retornos esperados BlackLitterman basados en opinión de expertos o rentabilidades históricas, y los obtenidos mediante la aplicación de Machine Learning, puntualmente los Support Vector Regression, lo que implica ponderaciones diferentes en las inversiones admisibles; en consecuencia, los portafolios reflejan el grado de incertidumbre de la matriz P frente a los views hallados bajo la utilización de Support Vector Regression y views basados en opinión de expertos, las diferencias se observan en la figura 19.

El modelo Black Litterman con Support Vector Regression genera mejores perspectivas en índices como Coltes, DTF y SPX; en este sentido, una diversificación mayor a la observada en el portafolio con view basado en opinión de expertos, sugiere una renta variable nacional como el índice de las 500 acciones más transadas de la bolsa de Estados Unidos y depósitos fijos a 90 días del mercado colombiano.

No obstante, ambos portafolios Black-Litterman cuentan con mejor diversificación frente a la observada en el Markowitz, que en forma resumida se puede comparar mediante los rendimientos generados por unidad de riesgo de la siguiente manera (tabla 10). 
Figura 19: Diferencias entre retornos

BLM

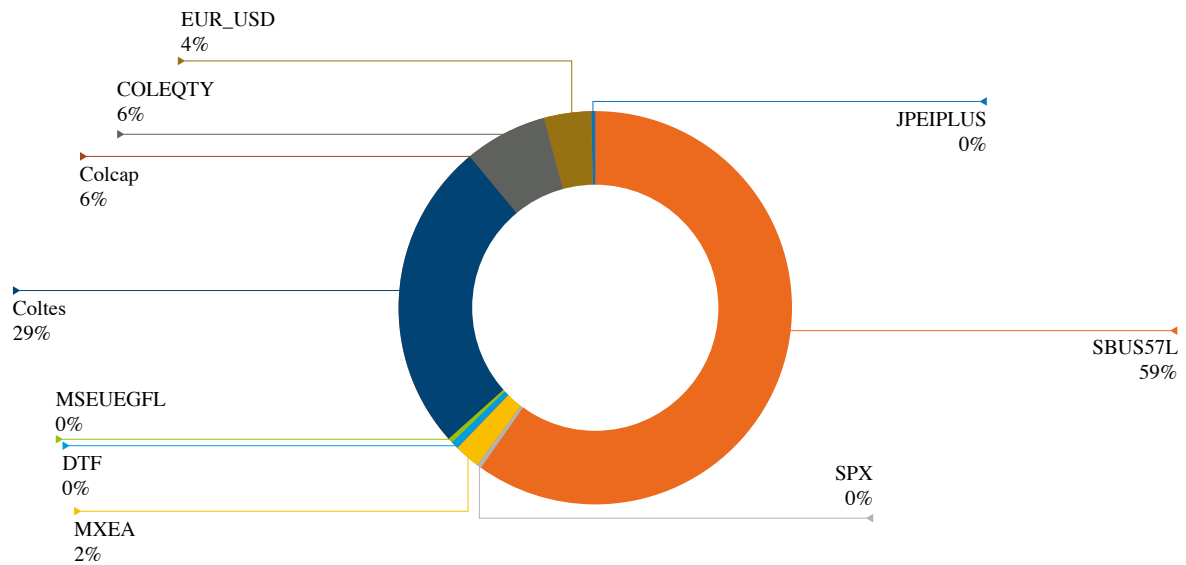

BLMSVR

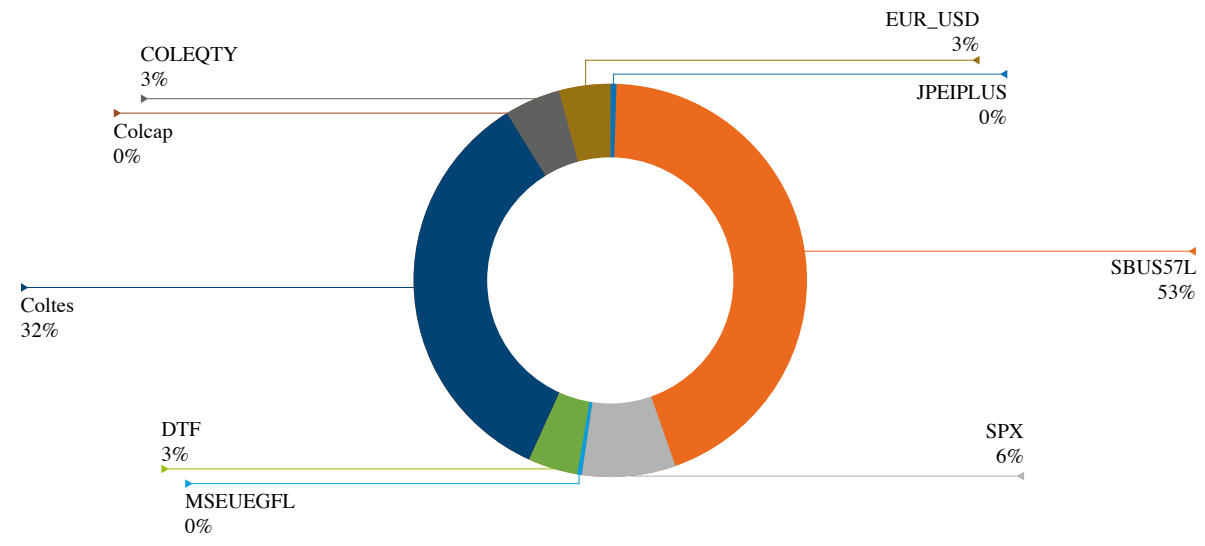

Fuente: elaboración propia.

Tabla 10: Comparación riesgo-retorno

\begin{tabular}{|c|c|c|}
\hline & $\sigma$ & $\sigma$ \\
\hline MARKOWITZ & $0,04 \%$ & $0,79 \%$ \\
\hline BLM & $0,05 \%$ & $0,14 \%$ \\
\hline BLM-SVR & $0,13 \%$ & $0,12 \%$ \\
\hline
\end{tabular}

Fuente: elaboración propia. 
En primera medida, la varianza del portafolio Markowitz excede a las de los respectivos portafolios BLM y BLM basado en Support Vector Regression (BML-SVR); de otra parte, ofrece una menor rentabilidad, por consiguiente, es un portafolio altamente concentrado y con menor rentabilidad por unidad de riesgo. En cuanto a los portafolios BLM y BLM-SVR, la varianza no es muy diferente, pero al tener en cuenta las rentabilidades se encuentra que el BLM-SVR ofrece una mejor rentabilidad para nivel de riesgo asociado, de manera tal que el portafolio BLM-SVR es eficiente en el sentido Sharpe.

En cuanto a la curva eficiente construida a través de la teoría tradicional y Black- Litterman y Black-Litterman con Support Vector Regression, se tiene (figura 20).

A pesar de que el portafolio de mínima varianza de ambas curvas parte de un nivel similar de varianza, es decir BLMsvr $\sigma=0,12 \%$ mientras que para BLM es de $\sigma=0,14 \%$, para este nivel de riesgo se evidencia una mejor rentabilidad en el portafolio BLMsvr $\mu=0,13 \%$ frente al rendimiento de $\mu=0,05 \%$ del modelo BLM.

Figura 20: Fronteras MV-BLM-BLMsvr

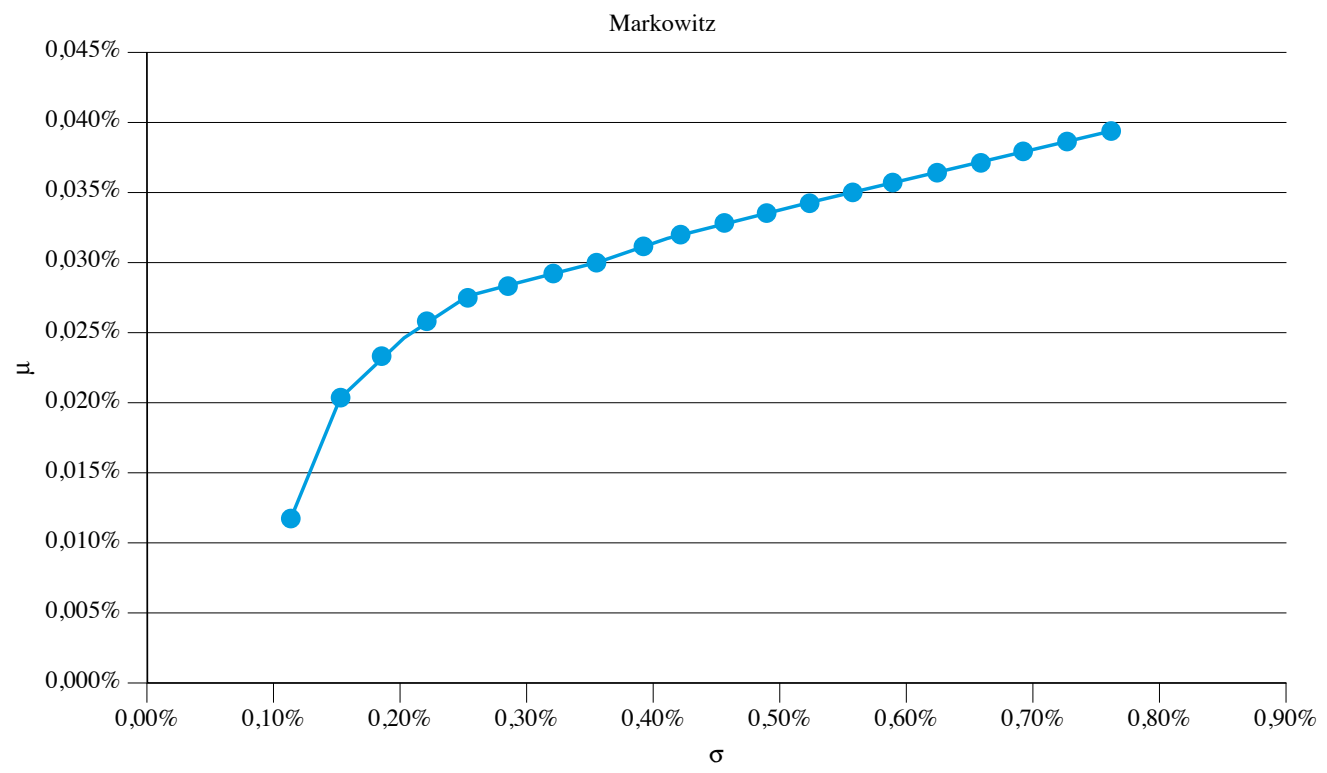



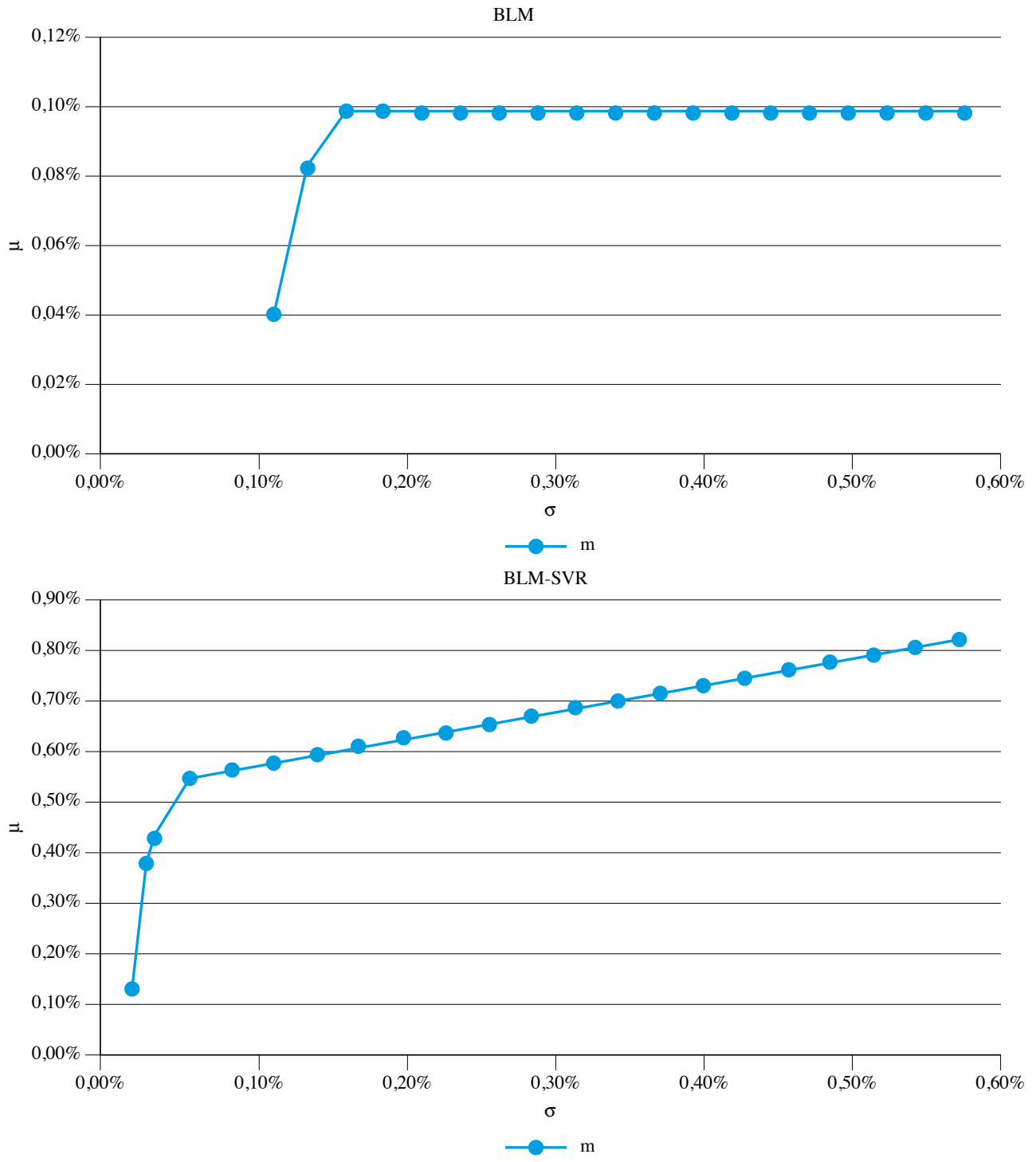

Fuente: elaboración propia.

De otra parte, a lo largo de la frontera eficiente se encuentra que la descrita por el modelo BLM tiende a aplanarse, en este sentido, para niveles de riesgo elevados se obtienen rentabilidades muy similares; en consecuencia, el exceso de rendimiento por unidad de riesgo descrito por esta curva no tendría mayor variación, y describiría de esta manera una curva inelástica, es decir, la rentabilidad es poco sensible ante niveles de riesgo crecientes. 
Al ubicar las rentabilidades del esquema multifondos para las cuatro administradoras y compararlas con la frontera creada bajo el modelo Black-Litterman con Support Vector Regression se obtiene (figura 21):

Figura 21: Frontera BLMsvr-Rendimientos FPO

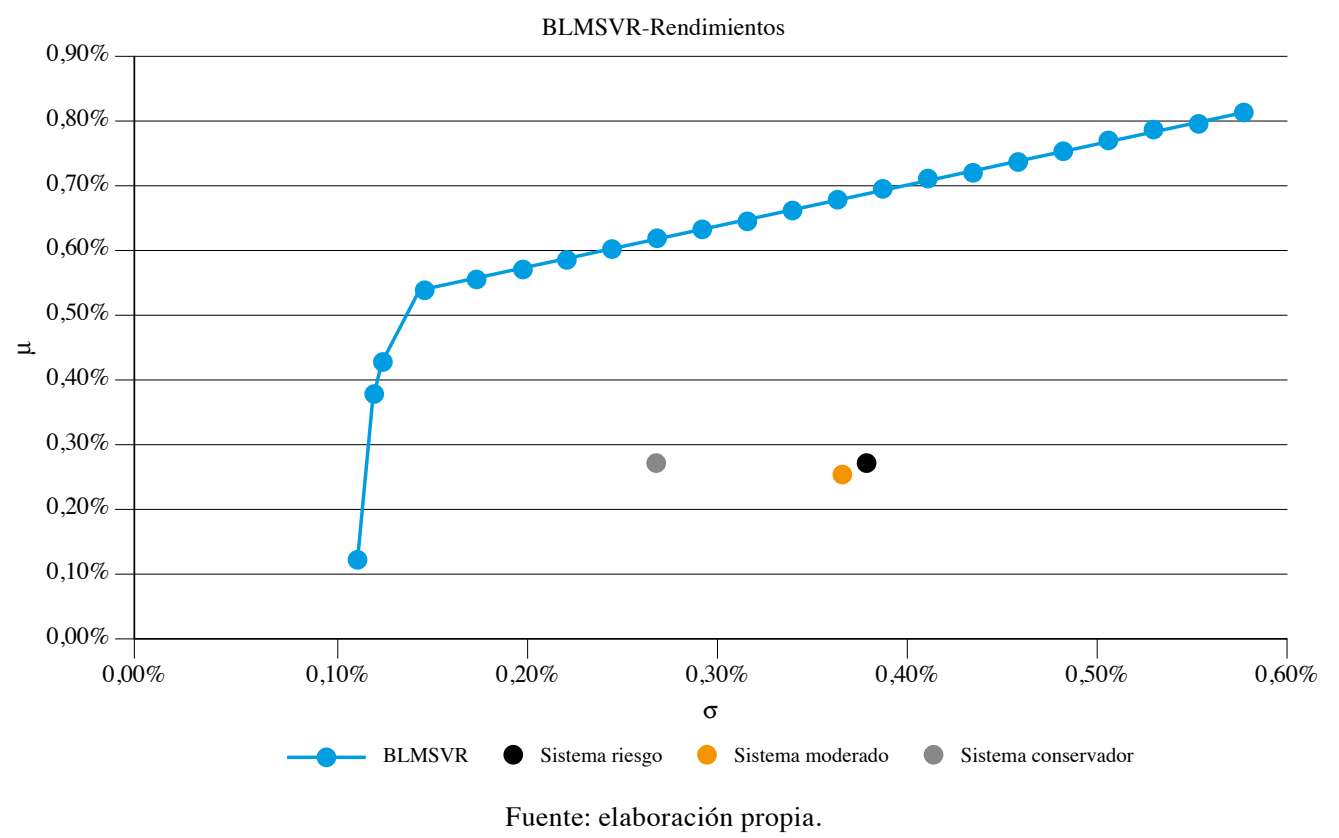

\section{Conclusiones y recomendaciones}

Mediante la comparación práctica realizada entre el modelo de Media-Varianza y el de Black-Litterman, se evidenció que el modelo Black-Litterman permite una mejor diversificación; adicionalmente, permite una participación directa por parte del administrador mediante opiniones y expectativas frente a las inversiones admisibles.

De otro lado, el análisis de la composición de los portafolios de las distintas AFP y la aplicación del índice de colusión invita a pensar que estas usan el modelo tradicional para la gestión de los portafolios, variando la participación de forma general en deuda local según la característica del fondo, es decir, moderado, riesgoso o conservador.

El índice en mención pone en evidencia lo inapropiado de la política de rentabilidad mínima, ya que se observa un efecto manada por parte de las 
administradoras, lo que genera portafolios subóptimos; adicionalmente, el portafolio sobre el cual se evidencia un mayor efecto manada es el conservador, reflejado en índices de Sharpe muy similares entre las administradoras, probablemente incentivadas por las medidas restrictivas de tipo normativo respecto de los límites de inversiones admisibles.

Las bondades del modelo Black-Litterman frente a la generación de portafolios con mejor diversificación pueden ser empleadas por parte de las AFP para contribuir con rentabilidades o mejor gestión sobre los fondos de retiro de los aportantes, y al contemplar las teorías desarrolladas en torno al Machine Learning, el modelo Black-Litterman puede ser mejorado, puntualmente mediante la generación de views absolutos con el uso de Support Vector Regression; en este sentido los administradores, en la medida que se afina el modelo y se evidencie un distanciamiento mayor frente a la RMO, provocarán un mejor dinamismo en el mercado, puesto que sus pares estarán preocupados por estructurar mejores portafolios para cautivar a los aportantes.

Finalmente, a raíz de la investigación realizada por Donthireddy (2018), donde se señala a Logit Regression y Sopport Vector Machine como clasificadores eficientes y su contribución al modelo Black-Litterman, convendría adelantar un estudio investigativo orientado a la aplicación a los FPO en el aspecto específico de la generación de views relativos que permitan a los administradores de fondos ejercicios comparativos frente a los efectos de diversificación al aplicar tanto views absolutos como relativos basados en Machine Learning.

\section{Referencias}

Carmona, E. (2014). Tutorial sobre máquinas de vectores soporte. Universidad Nacional de Educación a Distancia.

Departamento Administrativo Nacional de Estadística (DANE) (2018). Censo Nacional de Población y vivienda 2018. Boletín técnico. DANE.

Donthireddy, P. (2018). Black-Litterman Portfolios with Machine Learning derived Views Black-Litterman Portfolios with Machine Learning derived Views (July), 0-28. https://doi.org/10.13140/RG.2.2.26727.96160

Franco-Arbeláez, L. C., Avendaño-Rúa, C. T. y Barbutín-Díaz, H. (2011). Modelo de Markowitz y Modelo de Black-Litterman en la Optimización de Portafolios de Inversión. Journal of Finance, 7(1), 77-91. 
Idzorek, T. (2007). A step-by-step guide to the Black-Litterman model incorporating user-specified confidence levels. Forecasting Expected Returns in the Financial Markets, 2003, 17-38.

León, C., y Laserna, J. (2008). Asignación estratégica de activos para fondos de pensiones obligatorias en Colombia: un enfoque alternativo. Borradores de Economía, 523 (5). Recuperado de http://www.banrep.gov.co/docum/ftp/borra523. pdf?origin=publication_detail

López, H. y Lasso, F. (2012). El mercado laboral y el problema pensional colombiano. Borradores de Economia, 736 (72). Recuperado de http://www.banrep.gov.co/ sites/default/files/publicaciones/archivos/be_736.pdf

Pfaff, B. (2016). Financial risk modelling and portfolio optimization with $R$. John Wiley \& Sons.

Restrepo, C. G., Amezquita, A. P. y Jara, D. (2005). Analisis de eficiencia de los portafolios pensionales obligatorios en Colombia. Banco de la República, 1-32. Recuperado de https:/www.banrep.gov.co/sites/default/files/eventos/archivos/ JaraAFPs2005_0.pdf

Roy, A. (1952). Safety first and the holding of assets. Econometrica: Journal of the Econometric Society, 20(3), 431-449. Recuperado de http://www.jstor.org/stable/1907413

Rubinstein, M. (2006). A History of the Theory of Investments. John Wiley.

Rubinstein, M. (2010). Markowitz's Portfolio Selection: A fifty-year retrospective. The Journal of Finance, 57(3), 1041-1045.

Sharpe, W. F. (1966). Mutual Fund performance. The Journal of Business, 39(1), 119 138. https://doi.org/10.1086/294846

Trujillo Segura, M. E. (2009). Construcción y gestión de portafolios con el modelo BlackLitterman: una aplicación a los fondos de pensiones obligatorias en Colombia.

Villar, L., Malagón, J., Vaca, J. y Ruiz, C. (2013). Impactos macroeconómicos del sistema pensional en Colombia. Tendencia Económica, 64. Recuperado de http:// www.repository.fedesarrollo.org.co/handle/11445/346 